\title{
Application of Monte Carlo Simulation to Find Travel Time of Groundwater in the Iraqi Western Desert
}

\author{
Dawood Eisa Sachit ${ }^{1} \&$ Hayat Kareem Shukur Azawi ${ }^{2}$ \\ ${ }^{1}$ Environmental Engineering Department, Mustansiriyah University, Baghdad 10047, Iraq \\ ${ }^{2}$ Civil Engineering Department, Mustansiriyah University, Baghdad 10047, Iraq \\ Correspondence: Dawood Eisa Sachit, Environmental Engineering Department, Mustansiriyah University, \\ Baghdad 10047, Iraq. Tel: 964-772-268-3442. E-mail: dawood.sachit@okstate.edu
}

Received: November 25, 2017

Accepted: December 18, 2017

Online Published: December 21, 2017

doi:10.5539/enrr.v8n1p17

URL: https://doi.org/10.5539/enrr.v8n1p17

\begin{abstract}
In this study, a computerized mathematical method represented by Monte Carlo simulation was used to predict the travel time of the groundwater flow in the Iraqi western desert. During the run of the simulations, all the hydraulic parameters of Darcy's Law were fixed but the hydraulic conductivity. The input data of the hydraulic conductivity is compared to the triangular distribution function to find the best number of iteration to run the simulations. The results showed that an iteration number of 5000 was enough to achieve best match between the input data of the hydraulic conductivity and the fitted distribution function. In addition, the estimated travel time of the groundwater flow is broadly varied through the entire area and ranges from 1983 years to 113741 years based on $10000 \mathrm{~m}$ of travel distance. Furthermore, hydraulic conductivity of the aquifer has high impact on the estimated travel time of the groundwater flow. However, head difference of groundwater elevation among the selected wells considerably influences the expected travel time of the groundwater flow.
\end{abstract}

Keywords: Groundwater flow; Hydraulic conductivity; Monte Carlo simulation; Probability; Travel time.

\section{Introduction}

Increasingly, reliable predictions of groundwater flow and other hydraulic properties associated with uncertainties have been widely sought. Hence, various stochastic models to evaluate the uncertainty of groundwater problems have been developed. Uncertainty is defined as a situation of having lack of confidence in future outcomes as a result of unknown or inadequate input variables (Singh, Jain, \& Tyagi, 2007). In general, there are two types of method to analyze the uncertainty; analytical which uses models to propagate the uncertainty to estimate the probability distributions and empirical which uses computer simulation experiments to generate the distributions of the outputs (Doctor, Jacobson, \& Buchanan, 1988). Uncertainty of a system can be caused by natural activities such as those of environmental, hydrological, metrological or other natural processes which cause significant fluctuations in the space and time. In addition, inadequate data for a number of parameters which are required for risk analysis is a major source of the uncertainty in the system (Singh et al., 2007). To find or predict groundwater flow of an aquifer, it is necessary to identify the hydraulic properties of this aquifer. The parameters such as hydraulic conductivity or transmissivity, dispersivity, porosity, and hydraulic gradient, which influence the groundwater flow and transport, are taken into account as the main variables in constructing a stochastic model. However, lack of data of the hydraulic properties as a result of the heterogeneity of the natural porous media leads to the uncertainty of the groundwater flow problems (Neshat, Pradhan, \& Javadi, 2015). Additionally, it is well known that such parameters are characterized by spatial distribution throughout the aquifer and their values are randomly varied according to the point measurements (Crestani, Camporese, \& Salandin, 2015; Hassan, Bekhit, \& Chapman, 2009; Zhang \& San, 2000; Hoeksema \& Clapp, 1990). To produce a stochastic travel time of groundwater in a natural aquifer, a differential form of Darcy's law which is assumed to be valid for most groundwater flow is used (Zhang, Shi, Chang, \& Yang, 2010; Fitts, 2002; Zhang \& San, 2000). According to Darcy's law, travel time of groundwater flow is a function of travel distance, porosity, retardation factor, gradient, and hydraulic conductivity. Application of Darcy's law in groundwater flow problems and its advantages and limitations is well elaborated in literature.

Monte Carlo simulation technique is the most general method that deals with uncertainty analyses of complex systems to obtain numerical results (Singh et al., 2007; Li, McLaughlin, \& Liao, 2003). The simulation of the 
random samples mostly lies within the range of the input distribution. Monte Carlo analysis involves different types of distribution functions to generate a large number of random samples (Doctor et al., 1988). Some of the probability distributions are Triangular, Log Logistic, Beta General, Pearson5, Inve Gauss, and Log normal. In each distribution function, data can be simulated in different iterations up to 10000 iterations. Several researchers reported different numbers of iterations to represent the sample population. For example, Driels \& Shin (2004) indicated that running the simulation for 4684 iterations is accurate to $5 \%$ and gives a confidence interval of $95 \%$ for weapon effectiveness. Moreover, the number of the simulations also can be changed which results in a higher probability. The simulation is stopped when the desired confidence interval with a specific error has been achieved to produce a clear statistical description of dependent variables. However, using a larger number of simulations to achieve higher accuracy by generating more random numbers and increasing the sample size will generally increase the time consumed by the computer to finish the simulated run, which leads to high costs in complicated transient systems (Pasetto, Guadagnini, \& Putti, 2011; Singh et al., 2007). The results of the simulated data can be compared in many ways, one of which is by using fit comparison to the input or output data. A fit comparison graph (density or cumulative curves) combines both the input data and the fitted distribution in one graph in order to determine the location(s) of the best match area of the fitted distribution to the input data. A higher number of iterations gives a closer fit to the data (Palisade Corporation, 2008). The number of simulations can be fixed whenever the difference between the results of two or more simulations becomes insignificant.

Over the years, application of Monte Carlo simulation methods to estimate parameter uncertainty in groundwater hydrology has been widely used. Hoeksema and Clapp (1990), for instance, applied a Monte Carlo simulation to perform model calibration of a groundwater flow. Fu and Gómez-Hernández (2009), in another study, used Monte Carlo Markov chains to assess the uncertainty of groundwater flow and mass transport of a synthetic aquifer with three variables; conductivity, piezometric head, and travel time. They found that all three parameters impacted the uncertainty, and the piezometric head had the highest effect on uncertainty reduction. Similarly, a Monte Carlo Markov Chain method was also used by Hassan et al. (2009) to reduce the range of the input parameter distributions of a two dimensional groundwater flow model. For more studies see Zhang et al. (2010), Hassan et al. (2009), and Pasetto et al. (2011).

In this study, a computerized mathematical method represented by the Monte Carlo technique is used to estimate the likelihood of the travel time of the groundwater flow in several regions of the Iraqi western desert. The simulation included a sampling of hydraulic conductivity of the aquifers in the considered area.

\section{Description of Study Area}

The boundary of the considered area in this study is the Euphrates River from the east and north east and Iraq's border with Syria, Jordan, Saudi Arabia, and Kuwait from west and south as shown in Figure (1). The Iraqi western desert has several unconfined aquifers which are hydraulically connected to each other as well as some confined aquifers (Al-Fatlawi \& Jawad, 2011). The acceptable quality of the groundwater which is easy to access due to its closeness to the surface of the earth makes these aquifers a potential good source of water in this area (Al-Mussawi, 2014). Topographically, the north part of the area which is mostly covered with sandstone, clastic, and marl has a slope of about 0.002 from west to east. However, the southern part of the area which is generally covered with residual soil with calcium carbonate and chert has a lower slope toward the east. Geologically, limestone, dolomitic limestone, dolostone, marly limestone, sandstone, siltstone, claystone, marl, and evaporate are the most common rocks of the aquifers in the region of the Iraqi western desert (Al-Jiburi \& Al-Basrawi, 2009; Al-Jiburi \& Al-Basrawi, 2007). The rocks' diverse geological formations in the aquifers resulted in a wide range in the hydrogeological properties and hence uncertain hydraulic conductivity throughout this region. Therefore, the hydraulic conductivity of the aquifers in the Iraqi western desert has a broad range which is between $0.03 \mathrm{~m} /$ day and $100 \mathrm{~m} /$ day. The static groundwater level ranges from several meters to more than $300 \mathrm{~m}$ below the ground surface. The main source of the recharge to these aquifers is rainfall. The flow of the groundwater in the designated area is in the direction of the east and northeast (from west and southwest towards the Euphrates River). Additional information on the studied area is described elsewhere (Al-Jiburi \& Al-Basrawi, 2009; Al-Jiburi \& Al-Basrawi, 2007). 


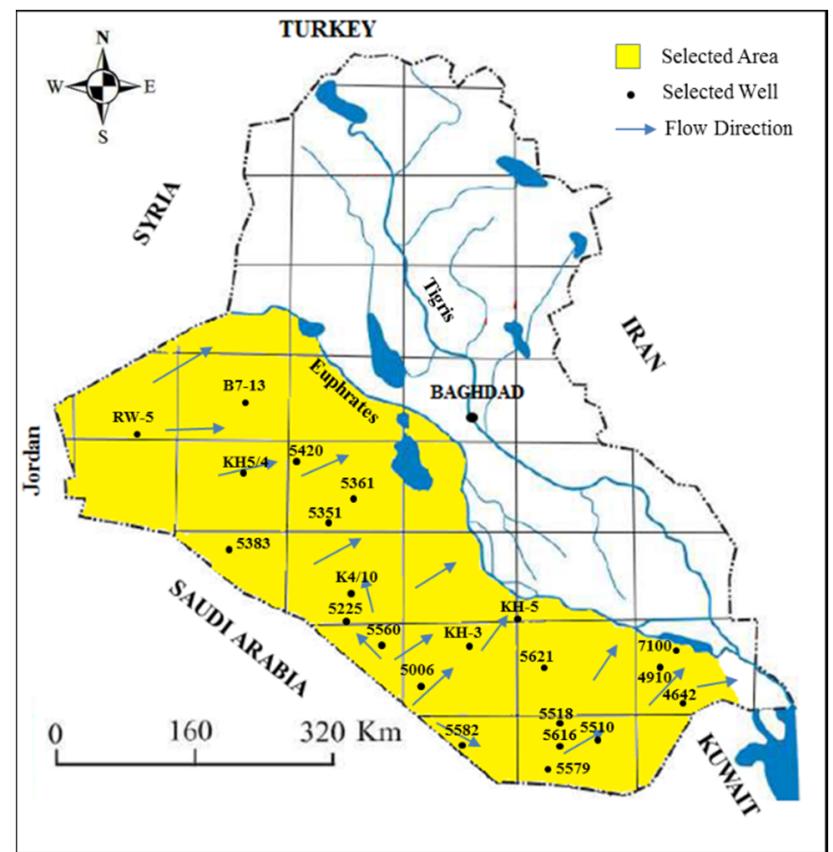

Figure 1. Location of the Considered Area (Adopted from Al-Jiburi \& Al-Basrawi (2009) and Al-Jiburi \& Al-Basrawi (2007))

\section{Methodology}

The available data of several wells located in the Iraqi western desert which are designated by the yellow color in Fig. 1 and listed in Table (1) as well as many existing wells in this region, which are described elsewhere (Al-Jiburi \& Al-Basrawi, 2009; Al-Jiburi \& Al-Basrawi, 2007), were used to run a computerized mathematical method represented by Monte Carlo simulation to estimate the travel time of the groundwater in this area. The locations of the selected wells represent nearly all the area of the Iraqi western desert. As previously mentioned, according to Darcy's law, travel time (T) is the function of the distance (L) for groundwater to travel, hydraulic gradient $(\mathrm{dh} / \mathrm{dl})$, porosity, and hydraulic conductivity $(\mathrm{K})$, and is expressed in the following formula (Todd \& Mays, 2005):

$$
T=-\frac{L}{\left(K * \frac{d h}{d l}\right)}
$$

Table 1. Selected Wells to Estimate Time of Travel for Groundwater in the Iraqi Western Desert

\begin{tabular}{cccc}
\hline Well No. & Ground surface above sea level $(\mathbf{m})$ & $\begin{array}{c}\text { Static water level below ground } \\
\text { surfaces }(\mathbf{m})\end{array}$ & $\begin{array}{c}\text { Hydraulic conductivity, } \\
\text { K (m/day) }\end{array}$ \\
\hline RW-5 & 622.1 & 25.7 & 0.03 \\
B7-13 & 385.7 & 205.3 & 19.4 \\
5383 & 490.4 & 296.4 & 9.2 \\
5351 & 280.4 & 90.9 & 0.7 \\
5383 & 490.4 & 296.4 & 9.2 \\
5361 & 199.2 & 103 & 12 \\
KH5/4 & 559 & 314 & 0.4 \\
5420 & 430 & 232 & 13.1 \\
5225 & 308 & 94.0 & 0.4 \\
K4/10 & 315 & 104.3 & 100 \\
5560 & 205 & 7.5 & 30.9 \\
KH-3 & 198 & 6.5 & 7.3 \\
5006 & 380 & 68.1 & 4.9 \\
5621 & 170 & 88 & 1.6 \\
5579 & 323 & 88.2 & 2.4 \\
5510 & 200 & 136 & 2.0 \\
5616 & 200 & 57.0 & 7.2 \\
4910 & 10 & 8.2 & 19.0 \\
\hline
\end{tabular}


In addition, it is well-known that the most affected parameter by the wide diversity of the natural lithologic material formation is the hydraulic conductivity the values of which cover an extensive range, even with very small hydrologic units. Therefore, in this study, all the parameters of Darcy's Law apart from the hydraulic conductivity were fixed. Again, Monte Carlo simulation can evaluate models with iterations up to 10000 and it is used to analyze the uncertain propagation of a model. The simulation involved the use of triangular distribution function to form the statistical analysis of the hydraulic conductivity. Triangular distribution is an easy probability function that is used in hydrologic and environmental engineering applications (Singh et al., 2007). To use triangular distribution function, three values, minimum, most likely, and maximum, of the hydraulic conductivity are needed. The hydraulic conductivity of all wells close to the selected wells in Figure (1) was considered in choosing the most likely value of the hydraulic conductivity to run the simulation. For example, wells 5818, 5875, 5987, 5994, 6845, 7055, B4/7, B13/7, BH-5, BH-16, KH5/1, KH5/2, KH5/4, KH5/5, $\mathrm{KH} 5 / 6, \mathrm{KH} 5 / 8, \mathrm{KH} 7 / 7, \mathrm{KH} 9 / 7, \mathrm{KH} 12 / 7$, and RW-3 which are reported by Al-Jiburi \& Al-Basrawi (2009), and Al-Jiburi \& Al-Basrawi (2007) were used to find the minimum, most likely, and maximum of the hydraulic conductivity in the area around and between wells (RW-5) and (B7-13). The other values of the minimum, most likely, and maximum of the hydraulic conductivity as well as the head difference, length $(L)$, and hydraulic gradient $(d h / d l)$ of each selected pair of wells are listed in Table (2) and were used to run the software of the Monte Carlo simulation to predict the travel time of the groundwater. Equation (1) which is used in Monte Carlo simulation to predict travel time of groundwater flow is expressed as follows:

$$
\text { Riskoutput("Travel Time, } T \text { ") }+\frac{L}{\left.(\text { Risktriang(minimum,most likely,maximum }) * \frac{d h}{d l}\right)}
$$

At the beginning, two different wells (RW-5) and (B7-13) were used to run several simulations by using different numbers of iterations to achieve smooth hydraulic conductivity and determine the best number for further simulations. A fit comparison graph for each run was used to determine the best match between the input data and the fitted distribution. If the best match is around the mean or along with tails, good results are most likely achieved (Palisade Corporation, 2008). The best number of iterations was used to assess the travel time of the groundwater for all selected pairs of wells.

Table 2. Hydraulic Parameters of the Selected Pairs of Wells Used in the Monte Carlo Simulation

\begin{tabular}{|c|c|c|c|c|c|c|}
\hline \multirow{2}{*}{ Well pairs } & \multicolumn{3}{|c|}{ Hydraulic conductivity, K (m/day) } & \multirow{2}{*}{$\begin{array}{l}\text { Head difference } \\
\text { (m) }\end{array}$} & \multirow{2}{*}{$\begin{array}{l}\text { Length, } L \\
\text { (m) }\end{array}$} & \multirow{2}{*}{$\begin{array}{c}\text { Hydraulic } \\
\text { gradient, } \\
\text { (dh/dl) }\end{array}$} \\
\hline & Minimum & Most likely & Maximum & & & \\
\hline $\begin{array}{l}\text { RW-5 } \\
\text { B7-13 }\end{array}$ & 0.03 & 1 & 19.4 & 416 & 134000 & 0.00310 \\
\hline $\begin{array}{l}5383 \\
5351\end{array}$ & 0.7 & 6.5 & 15.3 & 4.5 & 109670 & 0.00004 \\
\hline $\begin{array}{l}5383 \\
5361\end{array}$ & 0.5 & 5 & 15.3 & 97.8 & 139000 & 0.0007 \\
\hline $\begin{array}{c}\mathrm{KH} 5 / 4 \\
5420\end{array}$ & 0.4 & 5.38 & 13.1 & 47 & 59355 & 0.00079 \\
\hline $\begin{array}{c}5225 \\
\mathrm{~K} 4 / 10\end{array}$ & 0.3 & 19.5 & 100 & 3.3 & 25000 & 0.00013 \\
\hline $\begin{array}{l}5560 \\
\text { KH-3 }\end{array}$ & 0.3 & 4.5 & 30.9 & 6.0 & 87500 & 0.00007 \\
\hline $\begin{array}{l}5006 \\
5621\end{array}$ & 0.3 & 1.73 & 7.3 & 229.9 & 116670 & 0.00197 \\
\hline $\begin{array}{l}5579 \\
5510\end{array}$ & 0.1 & 2.9 & 17.9 & 170.8 & 54170 & 0.00315 \\
\hline $\begin{array}{l}5616 \\
4910\end{array}$ & 0.1 & 2.3 & 22.3 & 141.2 & 127080 & 0.00111 \\
\hline
\end{tabular}

\section{Results and Discussion}

As previously mentioned, wells (RW-5) and (B7-13) were used to run several simulations with different numbers of iterations to determine the best number that can be used for further simulations. Histograms of 
Figures 2, 3, 4, 5, 6, and 7 show the simulations that have been run with iteration number of 100, 500, 1000, 2000, 5000, and 10 000, respectively, to estimate the hydraulic conductivity between well (RW-50) and well (B7-13). The simulations, as previously mentioned, involved the use of the triangular function as a fitted distribution to compare it to the input data of the hydraulic conductivity. However, in Monte Carlo simulation, travel time within given hydrologic parameters most likely follows a lognormal distribution (Doctor et al., 1988). Therefore, lognormal density was used as a fitted distribution to compare it to the input data of the travel time. Histograms of Figures 2 through 6 explained that when the number of iteration was gradually increased, an obvious increase in the match between the input data of the hydraulic conductivity and the triangular distribution function was observed and the best fit was achieved at an iteration number of 5000. However, increasing the number of iteration to 10000 showed no significant difference to the 5000 iterations as shown in Figure 7 and compared to Figure 6. As a result, a number of 5000 iterations was used to run all the simulations to estimate the likelihood of the travel time of the groundwater flow of each selected pair of wells. Figures A1 through A8 (Appendix A) display fit comparisons between the input data of the hydraulic conductivity and the triangular distribution function for the selected pairs of the wells which are listed in Table (2).

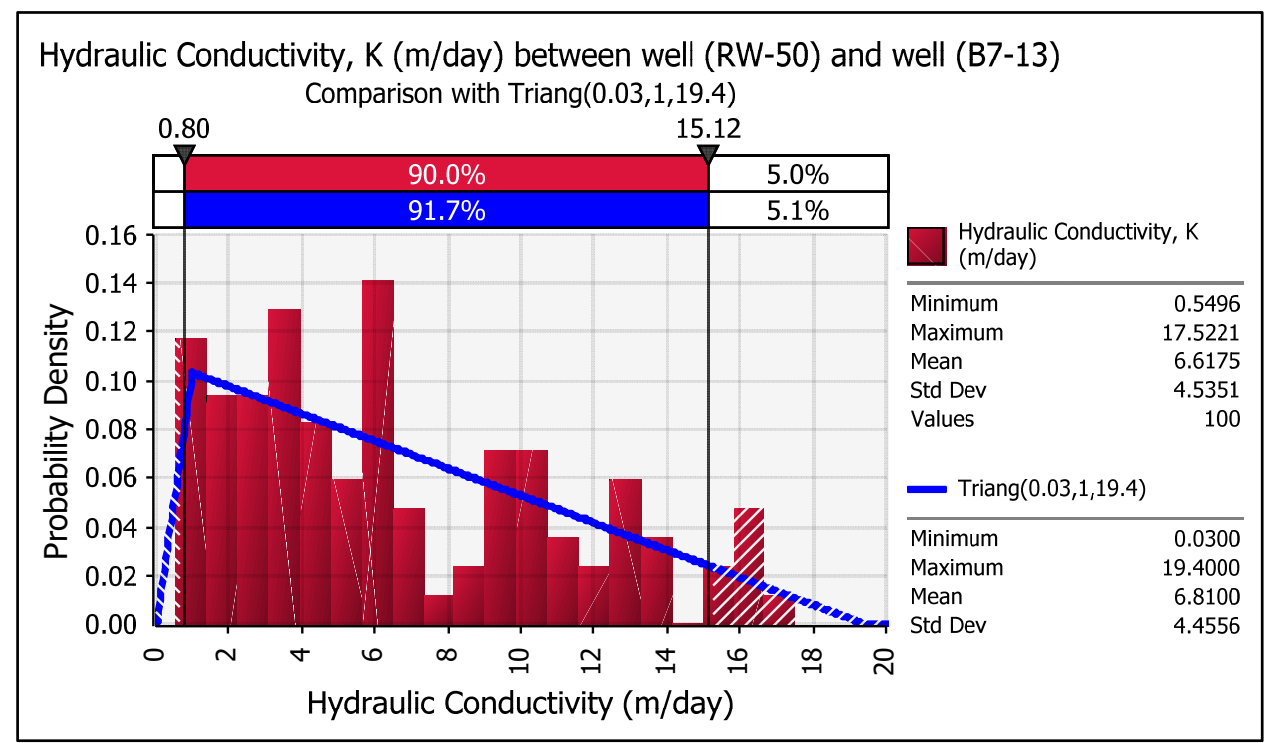

Figure 2. Hydraulic Conductivity between Well (RW-50) and Well (B7-13) with an Iteration Number of 100

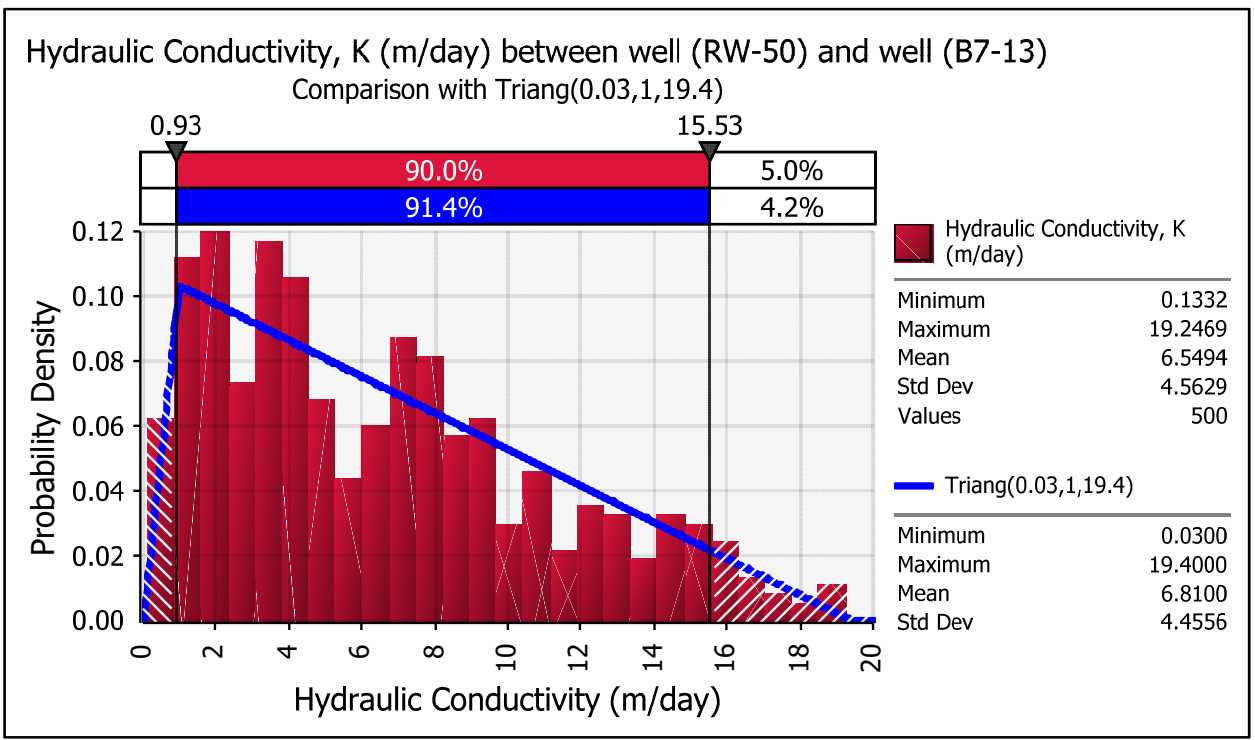

Figure 3. Hydraulic Conductivity between Well (RW-50) and Well (B7-13) with an Iteration Number of 500 


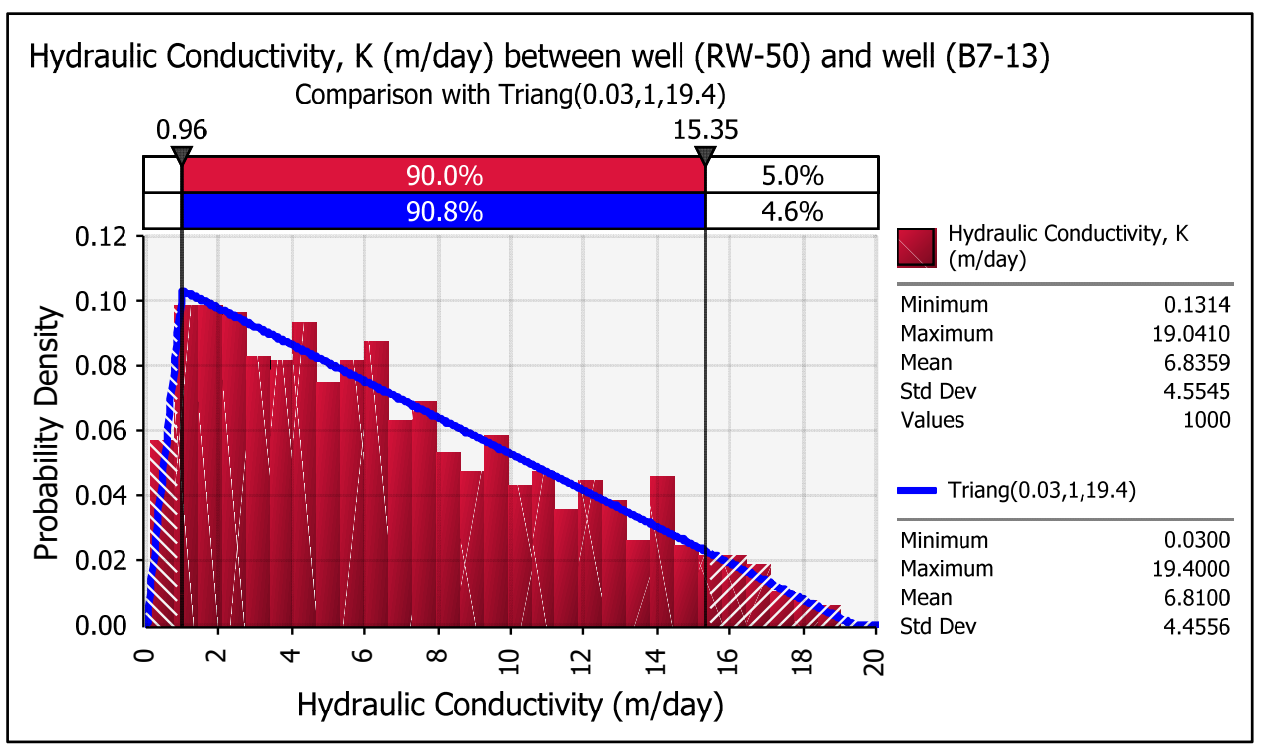

Figure 4. Hydraulic Conductivity between Well (RW-50) and Well (B7-13) with an Iteration Number of 1000

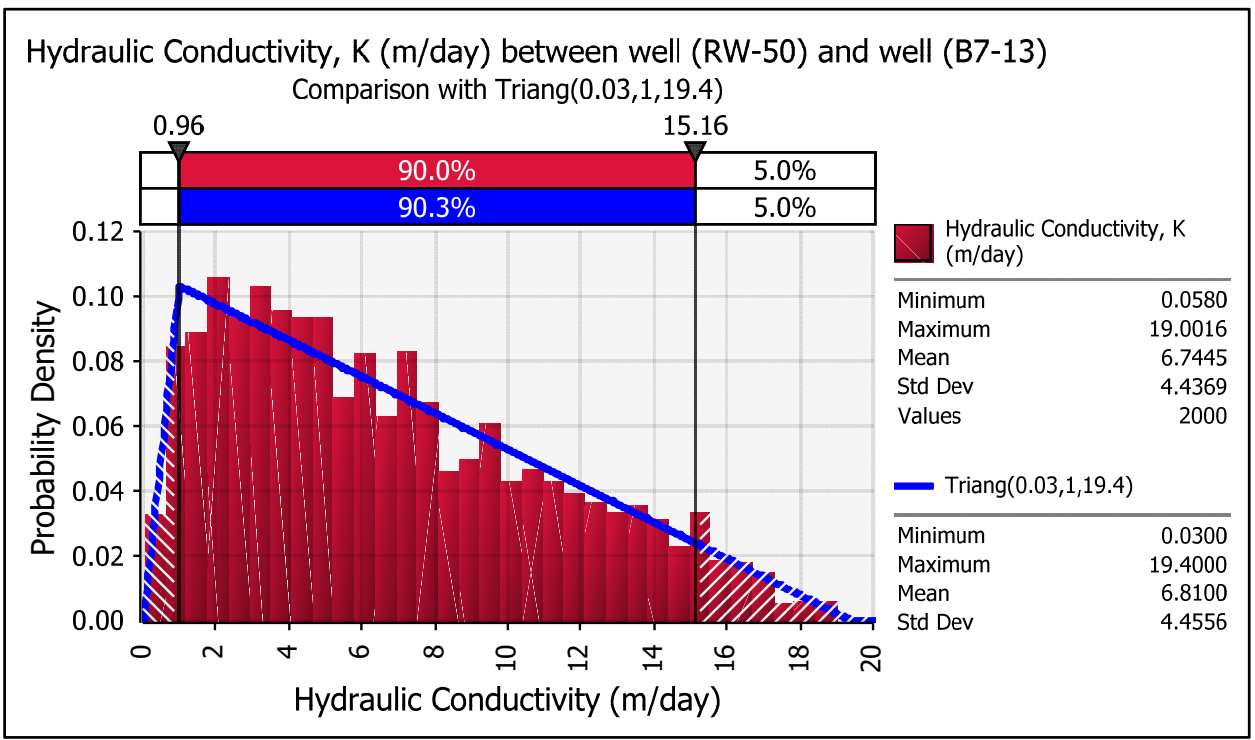

Figure 5. Hydraulic Conductivity between Well (RW-50) and Well (B7-13) with an Iteration Number of 2000 


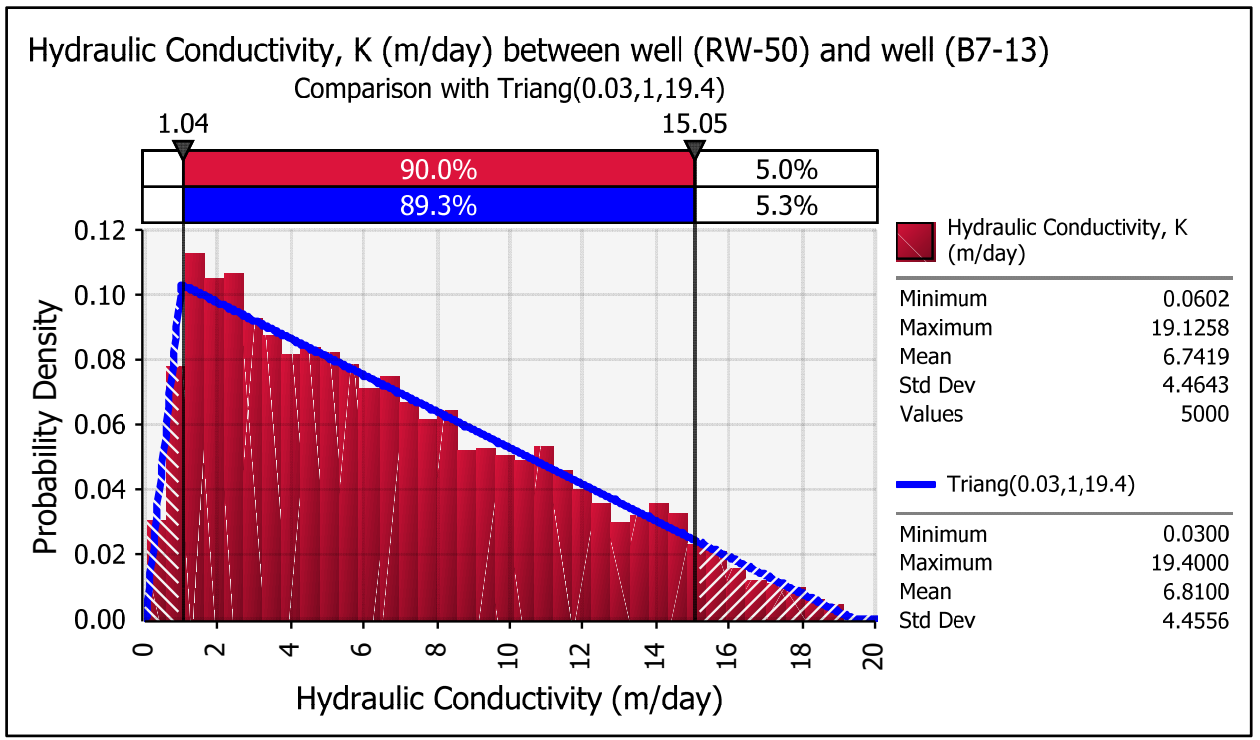

Figure 6. Hydraulic Conductivity between Well (RW-50) and Well (B7-13) with an Iteration Number of 5000

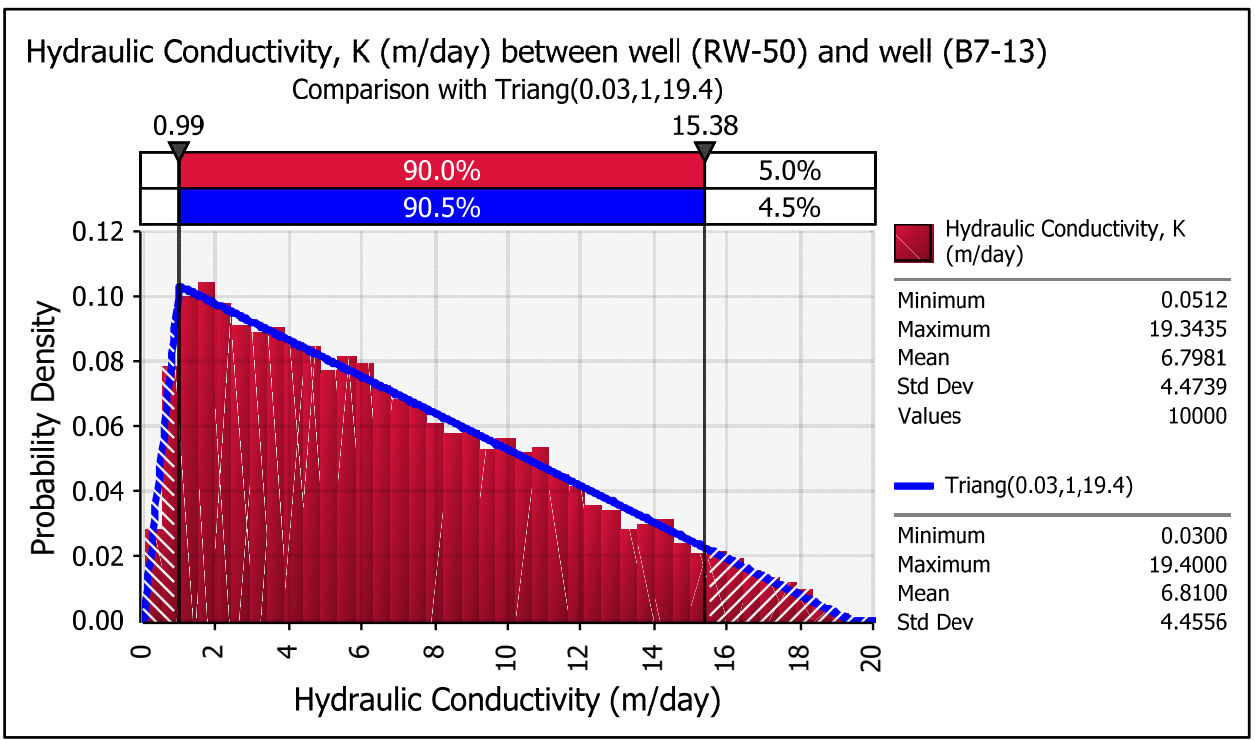

Figure 7. Hydraulic Conductivity between Well (RW-50) and Well (B7-13) with an Iteration Number of 10000

Figure 8 displays probability distribution of the stochastic travel time of groundwater flow between well (RW-50) and well (B7-13) with an iteration number of 5000. The probability distribution shows that $90 \%$ of the relative likelihood of occurrence for estimated travel time of groundwater flow falls within the range of 1560422 days (4275.129 years) to 410633898 days (1125 024 years) with a mean of 12293946 days (33 682.04 years) through a travel distance of $134000 \mathrm{~m}$. For the other selected pairs of wells in the Iraqi western desert, ranges and likelihoods of occurrence for travel time of the groundwater flow are shown in Figures 10 through 17 and the results are summarized in Table (3). The units of the estimated travel time shown in Table (3) which are expressed in days were converted to years to make it easier in the comparison. In addition, a fit comparison graph to determine the best match between the input data of travel time (between well (RW-50) and well (B7-13)) and lognormal density as a fitted distribution is illustrated in Figure 9. Furthermore, Figures B1 through B8 (Appendix B) display fit comparisons for the selected pairs of the wells which are listed in Table (2) and were used to run the software of the Monte Carlo simulation. 


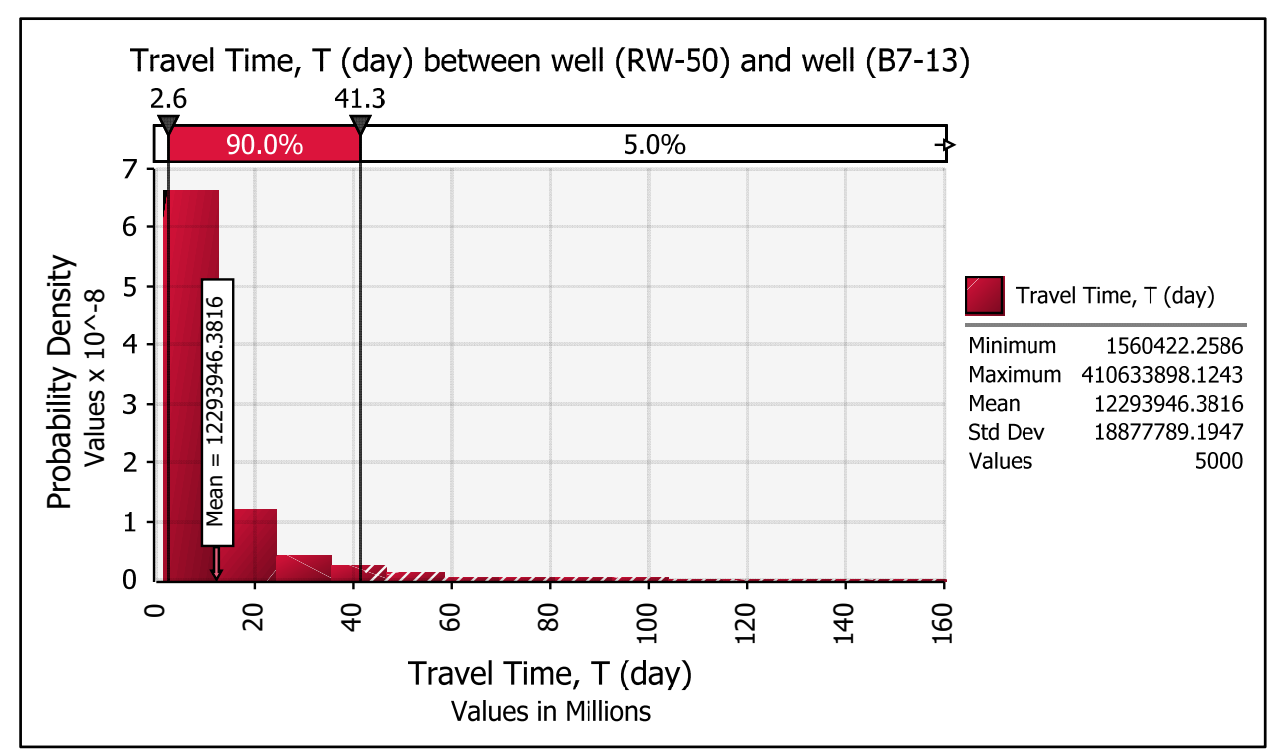

Figure 8. Probability Distribution of Travel Time of Groundwater Flow between Well (RW-50) and Well (B7-13) with an Iteration Number Of 5000

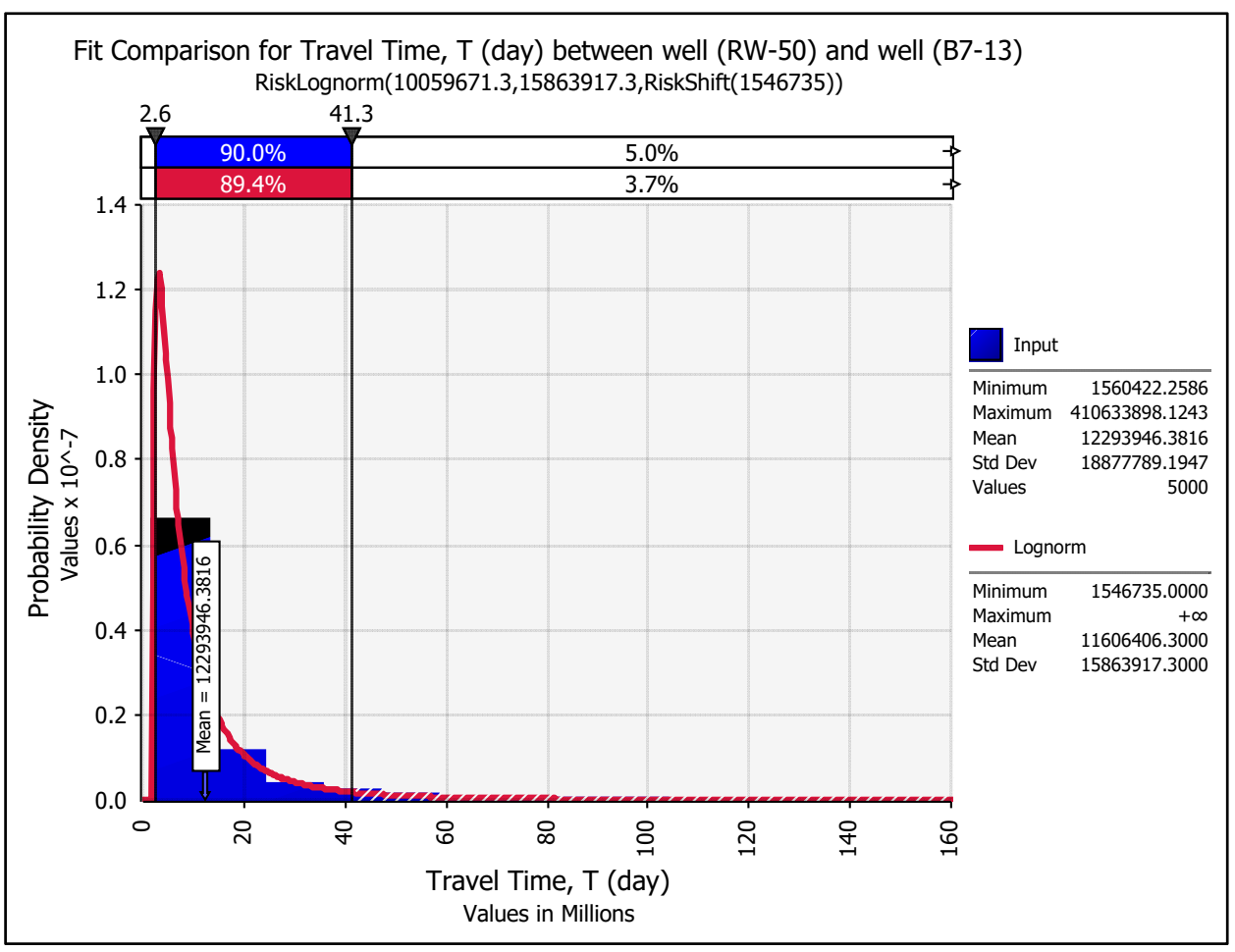

Figure 9. Fit Comparison for Travel Time between Well (RW-50) and Well (B7-13) 


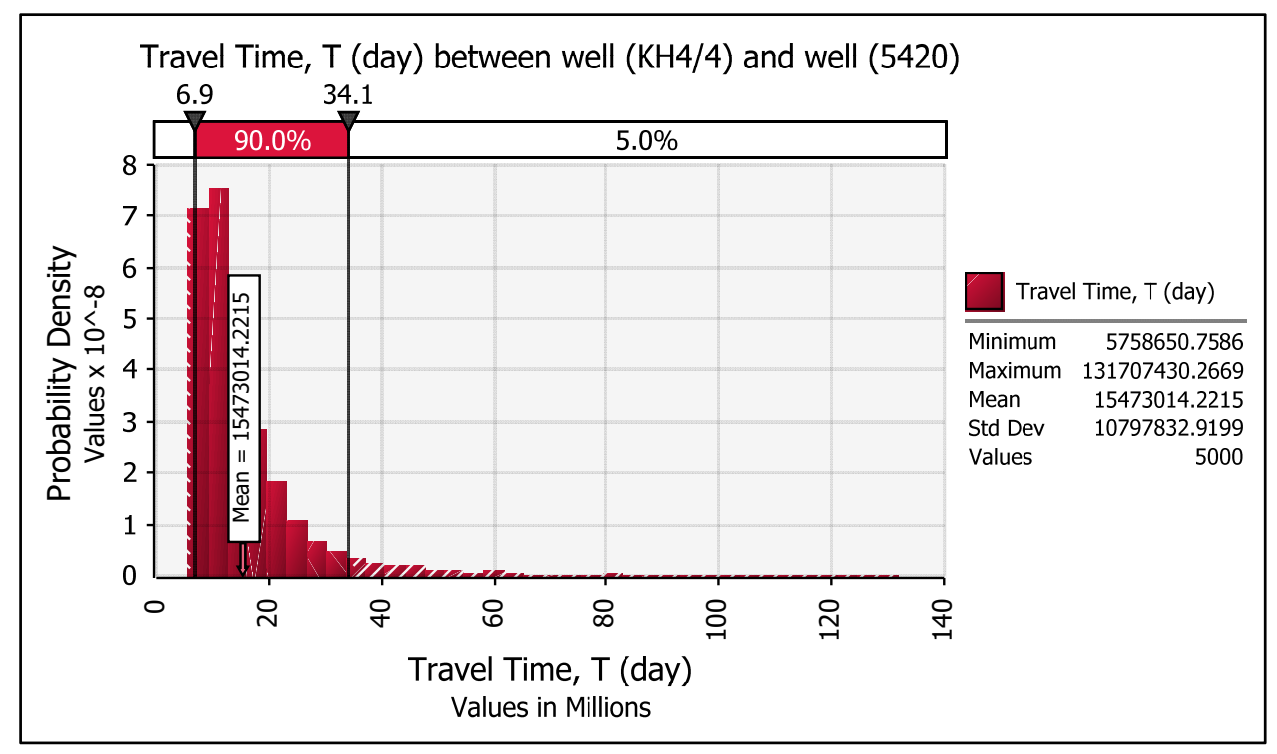

Figure 10. Probability Distribution of Travel Time of Groundwater Flow between Well (KH4/4) and Well (5420) with an Iteration Number of 5000

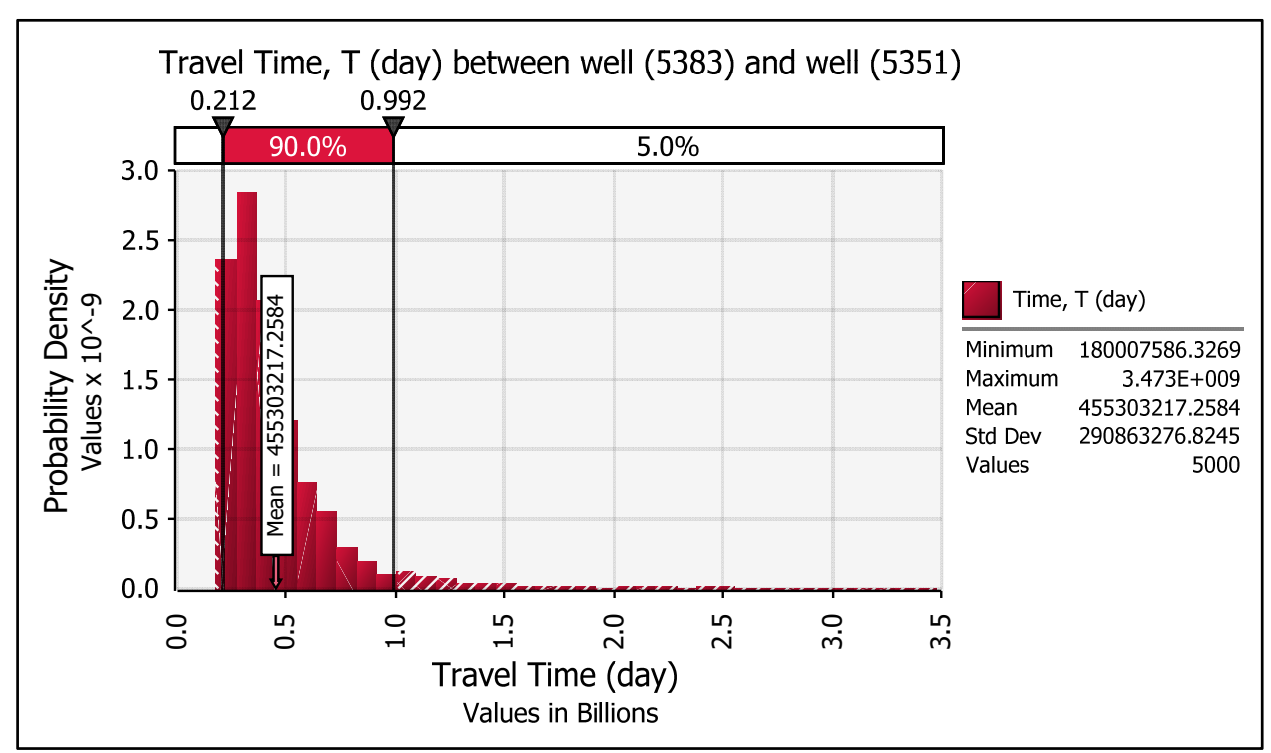

Figure 11. Probability Distribution of Travel Time of Groundwater Flow between Well (5383) and Well (5351) with an Iteration Number of 5000 


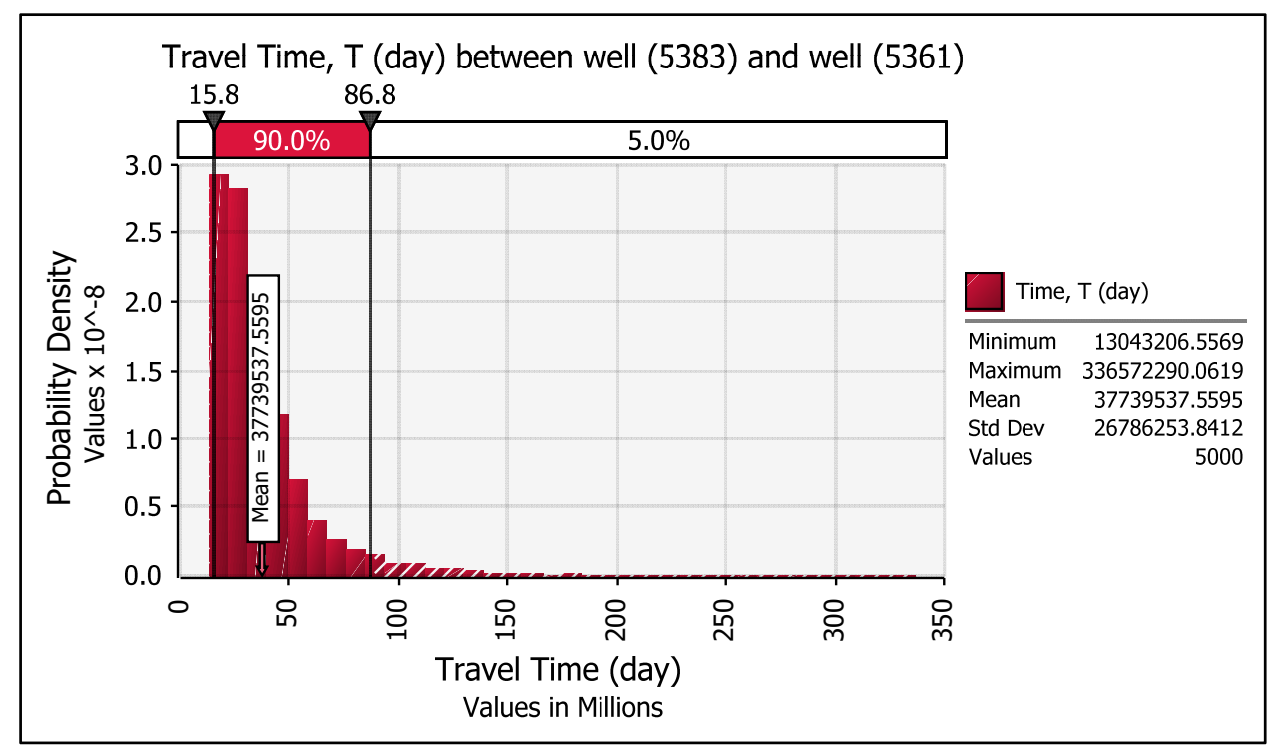

Figure 12. Probability Distribution of Travel Time of Groundwater Flow between Well (5383) and Well (5361) with an Iteration Number of 5000

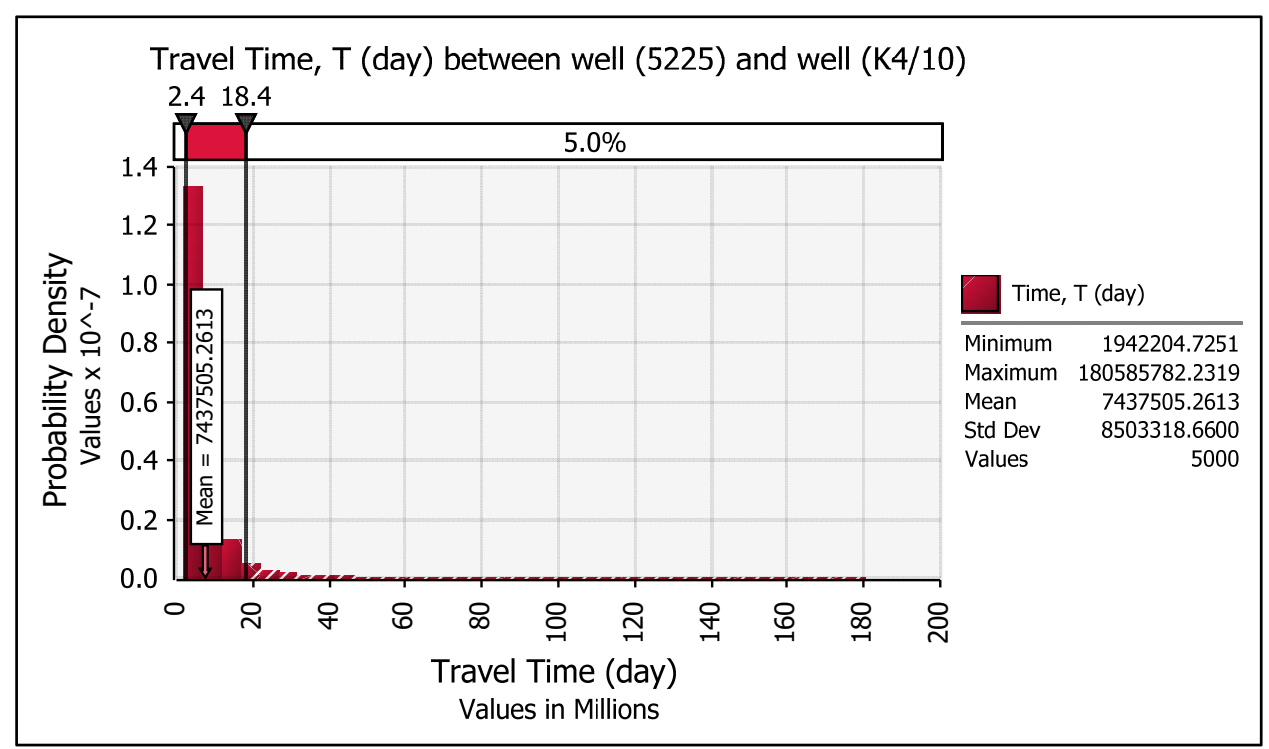

Figure 13. Probability Distribution of Travel Time of Groundwater Flow between Well (5225) and Well (K4/10) with an Iteration Number of 5000 


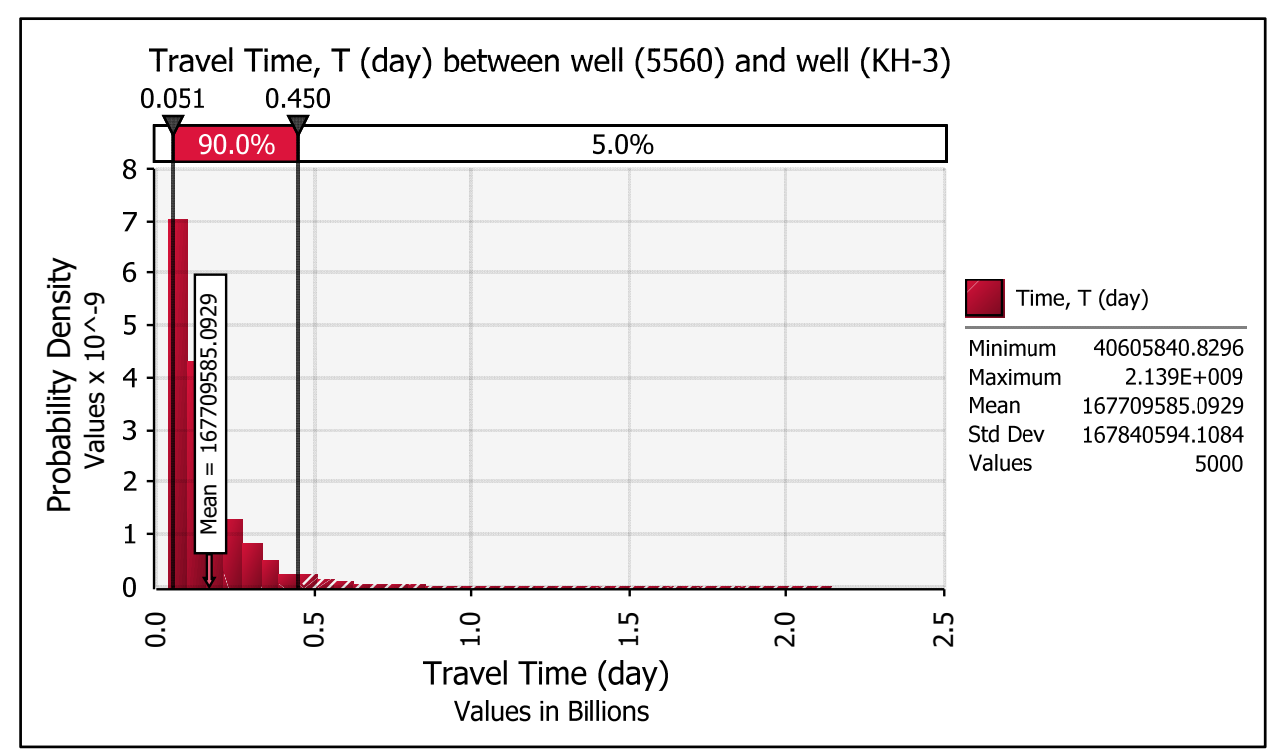

Figure 14. Probability Distribution of Travel Time of Groundwater Flow between Well (5560) and Well (KH-3) with an Iteration Number of 5000

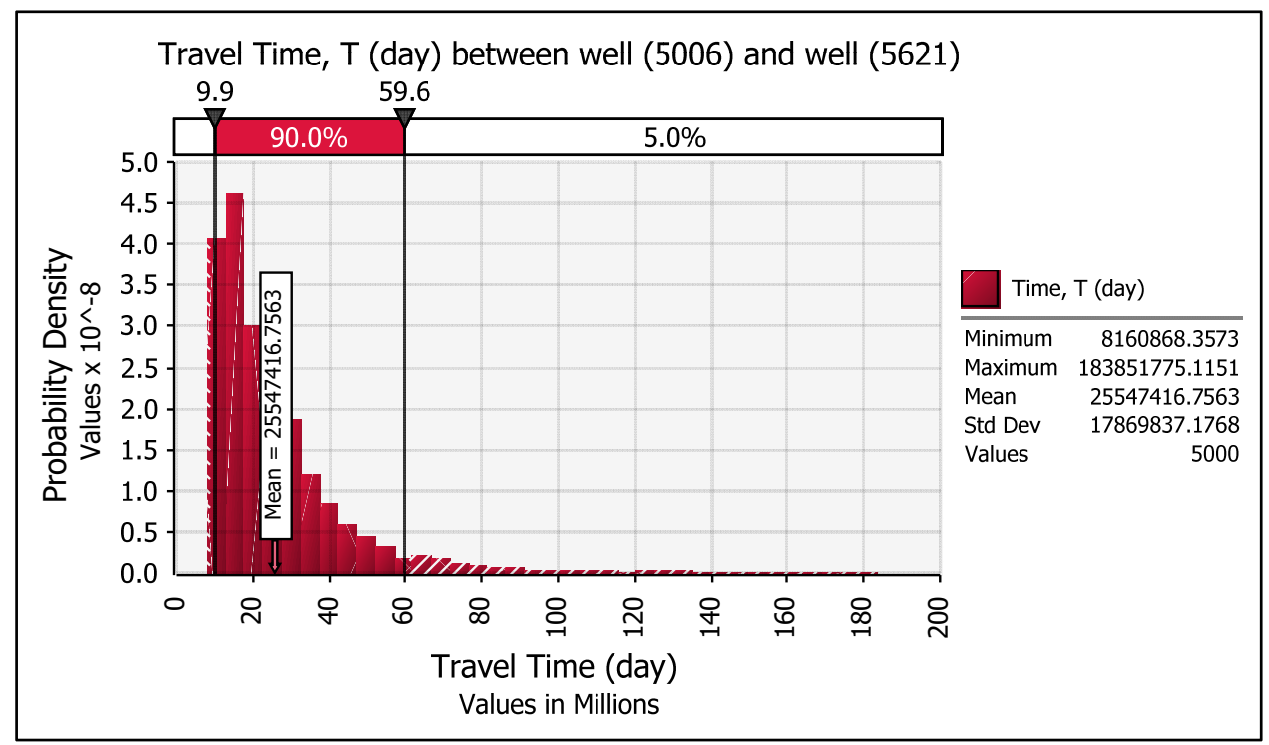

Figure 15. Probability Distribution of Travel Time of Groundwater Flow between Well (5006) and Well (5621) with an Iteration Number of 5000 


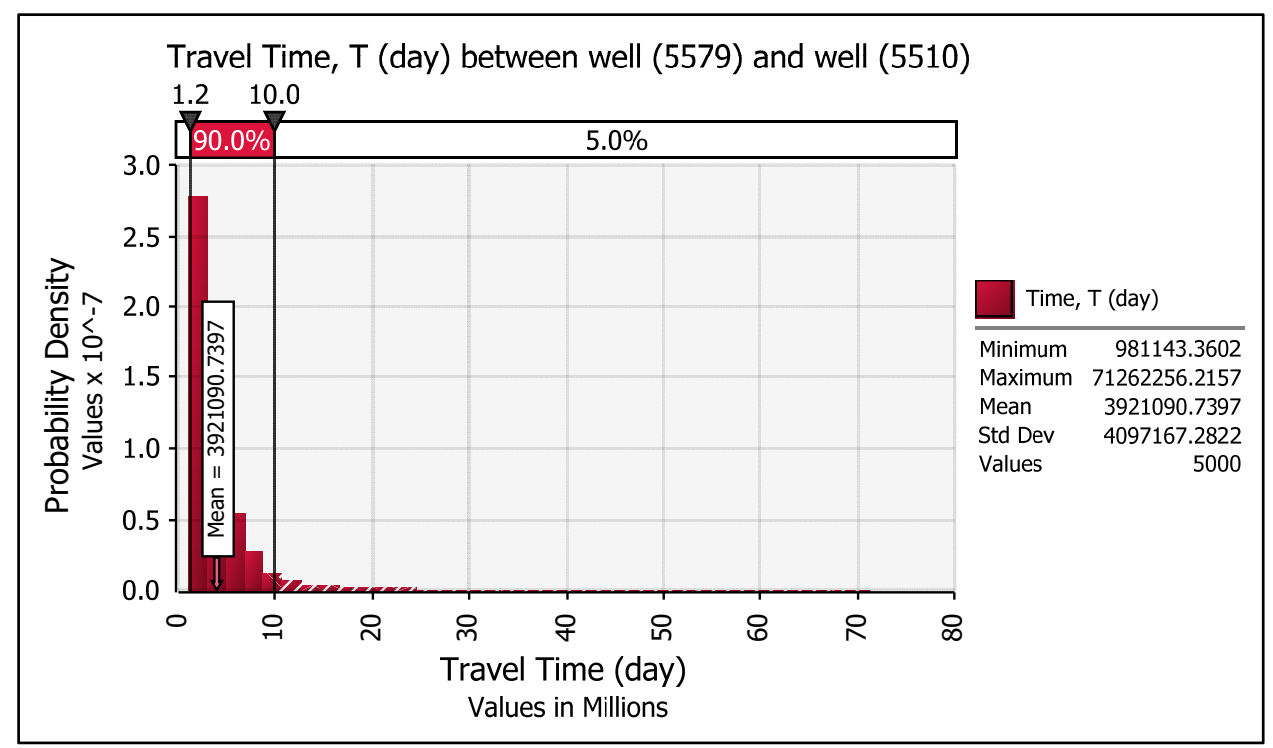

Figure 16. Probability Distribution of Travel Time of Groundwater Flow between Well (5579) and Well (5510) with an Iteration Number of 5000

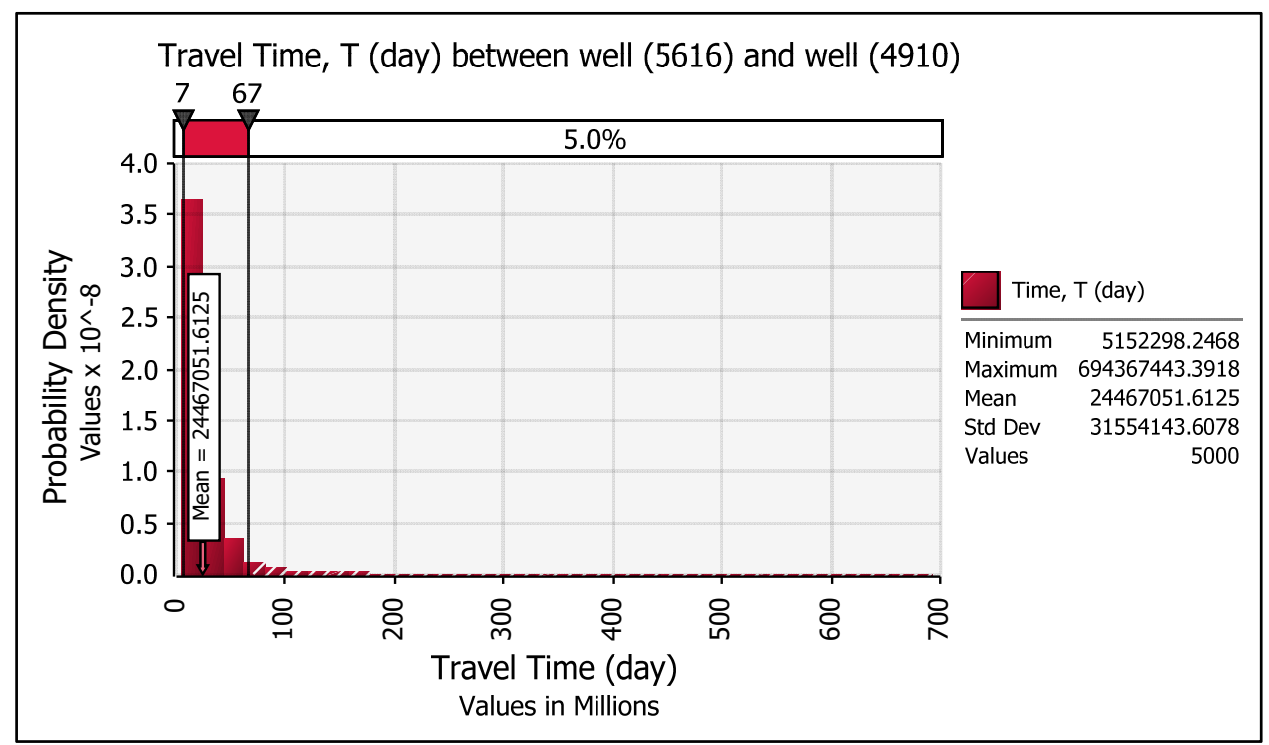

Figure 17. Probability Distribution of Travel Time of Groundwater Flow between Well (5616) and Well (4910) with an Iteration Number of 5000

Table (3) explains that the predicted travel time of the groundwater flow is varied through the entire Iraqi western desert which is the result of the wide range in hydrogeological properties of the geological formation in the aquifers. For example, the estimated mean travel time of the groundwater flow of the north part between well (RW-50) and well (B7-13) (which is 33682 years with travel distance of about $134000 \mathrm{~m}$ ) is about half of the estimated mean travel time of the southern part between well (5616) and well (4910) (which is 67033 years with travel distance of about $127080 \mathrm{~m}$ ). This is attributed to the higher values of the hydraulic conductivity of the geological formation of the southern part of the selected area. Moreover, although the travel distance between well (5383) and well (5361) which is $139000 \mathrm{~m}$ is higher than that between well (5383) and well (5351) which is $109670 \mathrm{~m}$, the estimated travel time of the groundwater flow between the first two wells (103 396 years) is much lower than that of the second two wells (1247 406 years). This is more likely because of the higher head difference of the groundwater elevation $(97.8 \mathrm{~m})$ between well (5383) and well (5361) compared to that of $4.5 \mathrm{~m}$ 
between well (5383) and well (5351) and as displayed in Table (2). Therefore, in addition to the hydraulic conductivity of the aquifers, head difference of the groundwater elevation highly influences the outputs of the simulations to predict travel time of groundwater flow. Over all, the histograms of the computerized mathematical method which is represented by Monte Carlo simulation revealed that the estimated travel time of the groundwater flow for the selected wells in the Iraqi western desert ranges from 1983 years to 113741 years based on $10000 \mathrm{~m}$ of travel distance. Moreover, fit comparison graphs to determine the best match between the input data of travel time and fitted distribution function show the same behavior for all selected wells. One of the advantages of assessing groundwater flow time to travel is to estimate travel time for a contaminant to reach discharge boundary. Therefore, it is recommended to apply Monte Carlo simulation on studying contaminant plumes in groundwater transport in this area.

Table 3. Summary of the Predicted Travel Time of Groundwater Flow for the Selected Pairs of Wells Used in the Monte Carlo Simulation

\begin{tabular}{|c|c|c|c|c|c|c|c|}
\hline \multirow{2}{*}{ Well pairs } & \multirow{2}{*}{$\begin{array}{c}\text { Length, } \\
\text { L(m) }\end{array}$} & \multicolumn{3}{|c|}{ Stochastic travel time, (day) } & \multicolumn{3}{|c|}{ Stochastic travel time, (year) } \\
\hline & & Minimum & Maximum & Mean & Minimum & Maximum & Mean \\
\hline $\begin{array}{l}\text { RW-5 } \\
\text { B7-13 }\end{array}$ & 134000 & 1560422 & 410633898 & 12293946 & 4275 & 1125024 & 33682 \\
\hline $\begin{array}{l}5383 \\
5351\end{array}$ & 109670 & 180007586 & 3473156375 & 455303217 & 493171 & 9515497 & 1247406 \\
\hline $\begin{array}{l}5383 \\
5361\end{array}$ & 139000 & 13043206 & 336572290 & 37739537 & 35734 & 922115 & 103396 \\
\hline $\begin{array}{c}\mathrm{KH} 5 / 4 \\
5420\end{array}$ & 59355 & 5758650 & 131707430 & 15473014 & 15777 & 360842 & 42391 \\
\hline $\begin{array}{c}5225 \\
\mathrm{~K} 4 / 10\end{array}$ & 25000 & 1942204 & 180585782 & 7437505 & 5321 & 494755 & 20376 \\
\hline $\begin{array}{c}5560 \\
\text { KH-3 }\end{array}$ & 87500 & 40605840 & 2139342017 & 167709585 & 111248 & 5861211 & 459478 \\
\hline $\begin{array}{l}5006 \\
5621\end{array}$ & 116670 & 8160868 & 183851775 & 25547416 & 22358 & 503703 & 69992 \\
\hline $\begin{array}{l}5579 \\
5510\end{array}$ & 54170 & 981143 & 71262256 & 3921090 & 2688 & 195239 & 10742 \\
\hline $\begin{array}{l}5616 \\
4910\end{array}$ & 127080 & 5152298 & 694367443 & 24467051 & 14115 & 1902377 & 67033 \\
\hline
\end{tabular}

\section{Conclusions}

Following conclusions are drawn from this study:

1) An iteration number of 5000 was enough to achieve best match between the input data of the hydraulic conductivity and the triangular distribution function.

2) As the hydrogeological properties of the Iraqi western desert are significantly varied, the expected travel time of the groundwater flow is widely varied as indicated by the histograms which resulted from Monte Carlo simulations.

3) As indicated by several studies, hydraulic conductivity of the aquifer has a high impact on the estimated travel time of the groundwater flow. However, head difference of groundwater elevation among the selected wells considerably influences the expected travel time of the groundwater flow.

\section{References}

Al-Fatlawi, A. N., \& Jawad, S. B. (2011). Water surplus for Umm Er Radhuma aquifer - west of Iraq. Euphrates Journal of Agriculture Science, 3(4), 1-10. Retrieved from https://iasj.net/iasj?func=fulltext\&aId=37312

Al-Jiburi, H. K., \& Al-Basrawi, N. H. (2007). Hydrogeology. In: Geology of Iraqi Western Desert. Iraqi Bull. Geol. Min., Special Issue(1), 125 - 144. Retrieved from https://www.iasj.net/iasj?func=fulltext\&aId=92951

Al-Jiburi, H. K., \& Al-Basrawi, N. H. (2009). Hydrogeology. In: Geology of Iraqi Southern Desert. Iraqi Bull. Geol. Min., Special Issue(2), 77 - 91. Retrieved from https://www.iasj.net/iasj?func=fulltext\&aId=61545 
Al-Mussawi, W. A. (2014). Assessment of groundwater quality in UMM ER Radhuma aquifer (Iraqi western desert) by integration between irrigation water quality index and GIS. Journal of Babylon University Engineering Sciences, 22(1), 201-2017.

Crestani, E., Camporese, M., \& Salandin, P. (2015). Assessment of hydraulic conductivity distributions through assimilation of travel time data from ERT-monitored tracer tests. Advanced in Water Resources, 84, 23-36. https://doi.org/10.1016/j.advwatres.2015.07.022

Doctor, P. G., Jacobson, E. A., \& Buchanan, J. A. (1988). A comparison of uncertainty analysis methods using a groundwater flow model. Pacific Northwest Lab., Richland, WA (USA). Retrieved from https://inis.iaea.org/search/search.aspx?orig_q=RN:20009155

Driels, M. R., \& Shin, Y. S. (2004). Determining the number of iterations for Monte Carlo simulations of weapon effectiveness. Naval Postgraduate School (U.S.), Defense Threat Reduction Agency, AD-a423 541. Retrieved from http://hdl.handle.net/10945/798

Fitts, C. R. (2002). Groundwater Science. Academic Press, An Imprint of Elsevier Science.

Fu, J., \& Gómez-Hernández, J. J. (2009). Uncertainty assessment and data worth in groundwater flow and mass transport modeling using a blocking Markov chain Monte Carlo method. Journal of Hydrology, 364, 328 341. https://doi.org/10.1016/j.jhydrol.2008.11.014

Hassan, A. E., Bekhit, H. M., \& Chapman, J. B. (2009). Using Markov Chain Monte Carlo to quantify parameter uncertainty and its effect on predictions of a groundwater flow model. Environmental Modeling \& Software, 24, 749-763. https://doi.org/10.1016/j.envsoft.2008.11.002

Hoeksema, R. J., \& Clapp, R. B. (1990). Calibration of groundwater flow models using Monte Carlo simulations and geostatistics. In ModelCARE 90: Calibration and Reliability in Groundwater Modeling, 33-42. IAHS Publ. 195.

Li, S. G., McLaughlin, D., \& Liao, H. S. (2003). A computationally practical method for stochastic groundwater modeling. Advanced in Water Resources, 26, 1137-1148. https://doi.org/10.1016/j.advwatres.2003.08.003

Neshat, A., Pradhan, B., \& Javadi, S. (2015). Risk assessment of groundwater pollution using Monte Carlo approach in an agricultural region: An example from Kerman Plain, Iran. Computers, Environment and Urban Systems, 50, 66-73. https://doi.org/10.1016/j.compenvurbsys.2014.11.004

Palisade Corporation, (2008). Guide to using @RISK: risk analysis and simulation add-in for Microsoft Excel, Version 5.0.

Pasetto, D., Guadagnini, A., \& Putti, M. (2011). POD-based Monte Carlo approach for the solution of regional scale groundwater flow driven by randomly distributed recharge. Advances in Water Resources, 34, 1450 1463. https://doi.org/10.1016/j.advwatres.2011.07.003

Singh, V. P., Jain, S. K., \& Tyagi, A. K. (2007). Risk and reliability analysis: a handbook for civil and environmental engineers. ASCE Press. Reston, Virginia.

Todd, D. K., \& Mays, L. W. (2005). Groundwater Hydrology ( $3^{\text {rd }}$ Edition). John Wiley \& Sons, Inc., New York.

Zhang D., Shi, L., Chang, H., \& Yang, J. (2010). A comparative study of numerical approaches to risk assessment of contaminant transport. Stoch Environ Res Risk Assess, 24, 971-984. https://doi.org/10.1007/s00477-010-0400-5

Zhang, D., \& Sun, A. Y. (2000). Stochastic analysis of transient saturated flow through heterogeneous fractured porous media: A double-permeability approach. Water Resources Research, 36(4), 865-874. http://dx.doi.org/10.1029/2000WR900003 


\section{Appendix A}

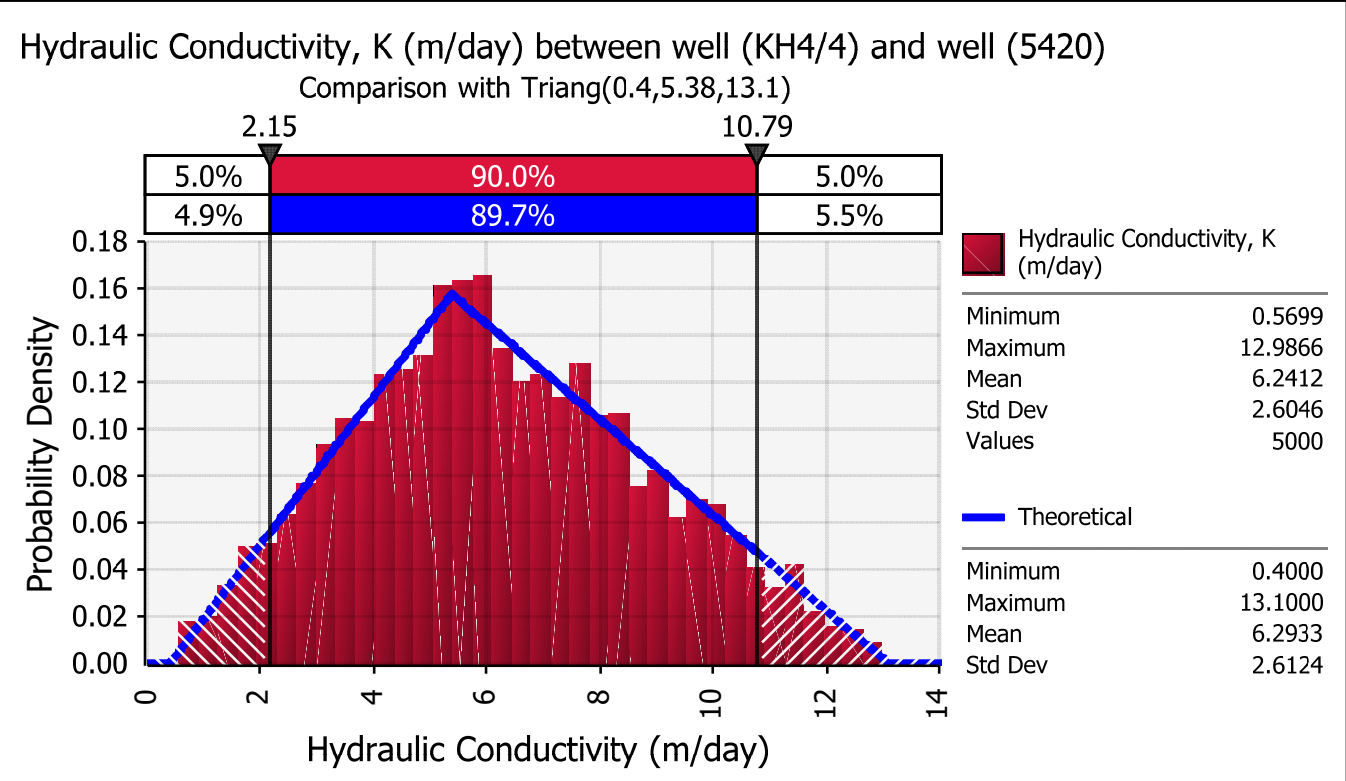

Figure A1. Hydraulic Conductivity between Well (KH4/4) and Well (5420) with an Iteration Number of 5000

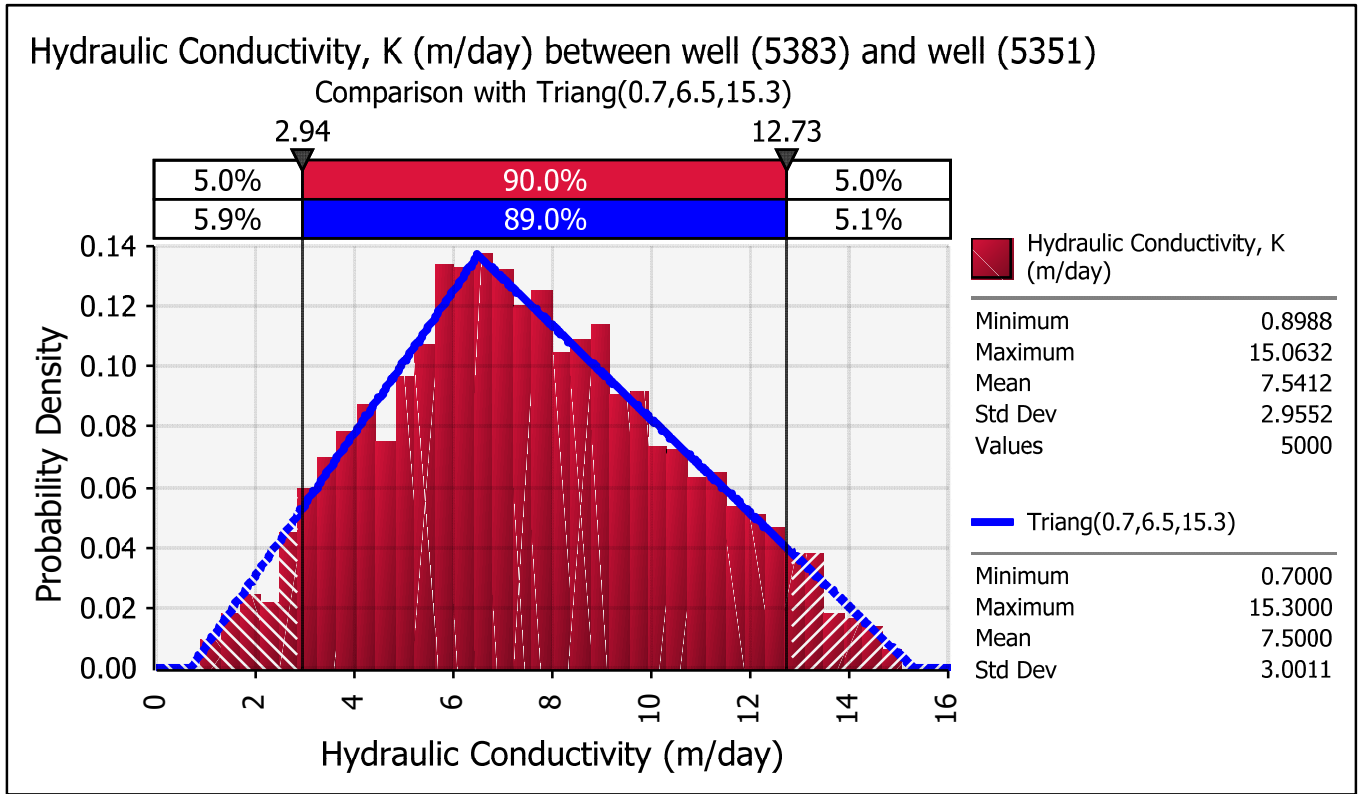

Figure A2. Hydraulic Conductivity between Well (5383) and Well (5351) with an Iteration Number of 5000 


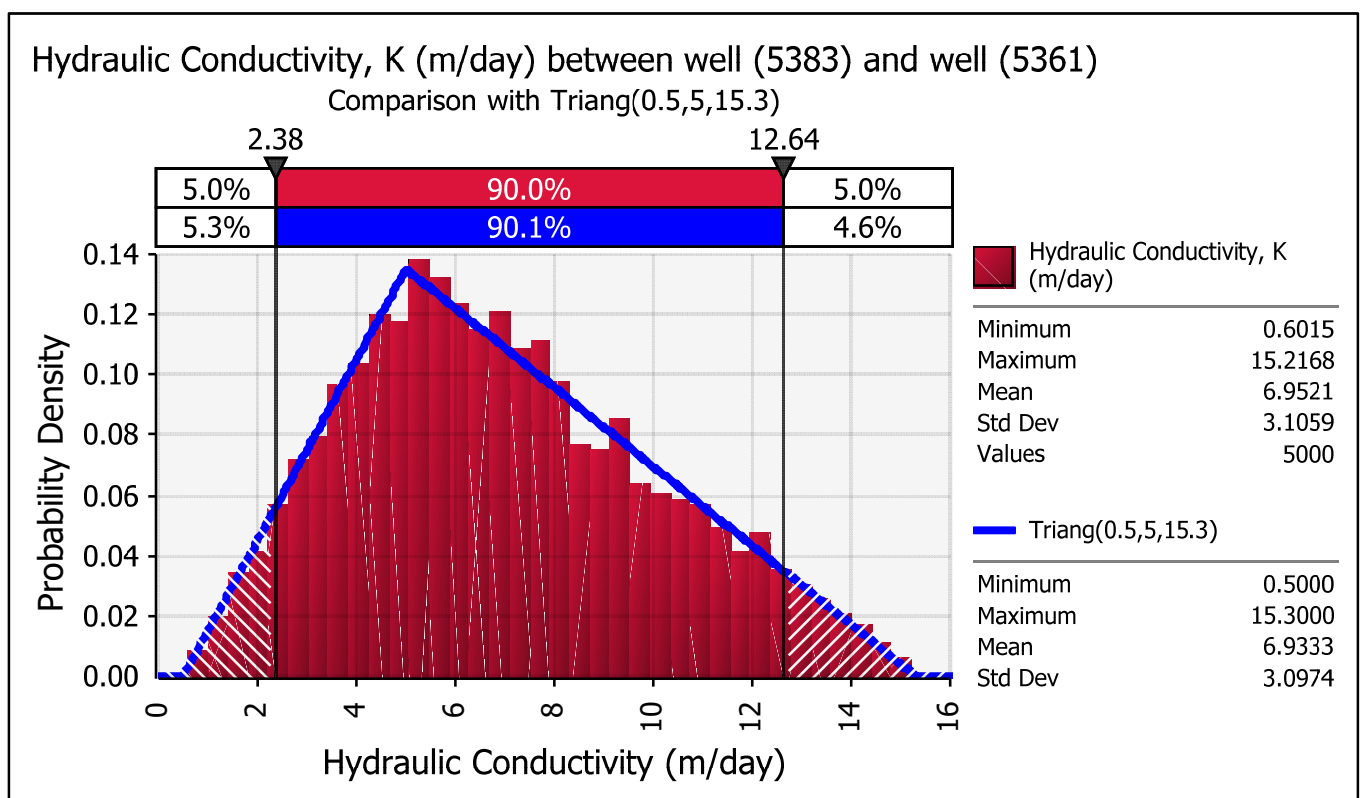

Figure A3. Hydraulic Conductivity between Well (5383) and Well (5361) with an Iteration Number of 5000

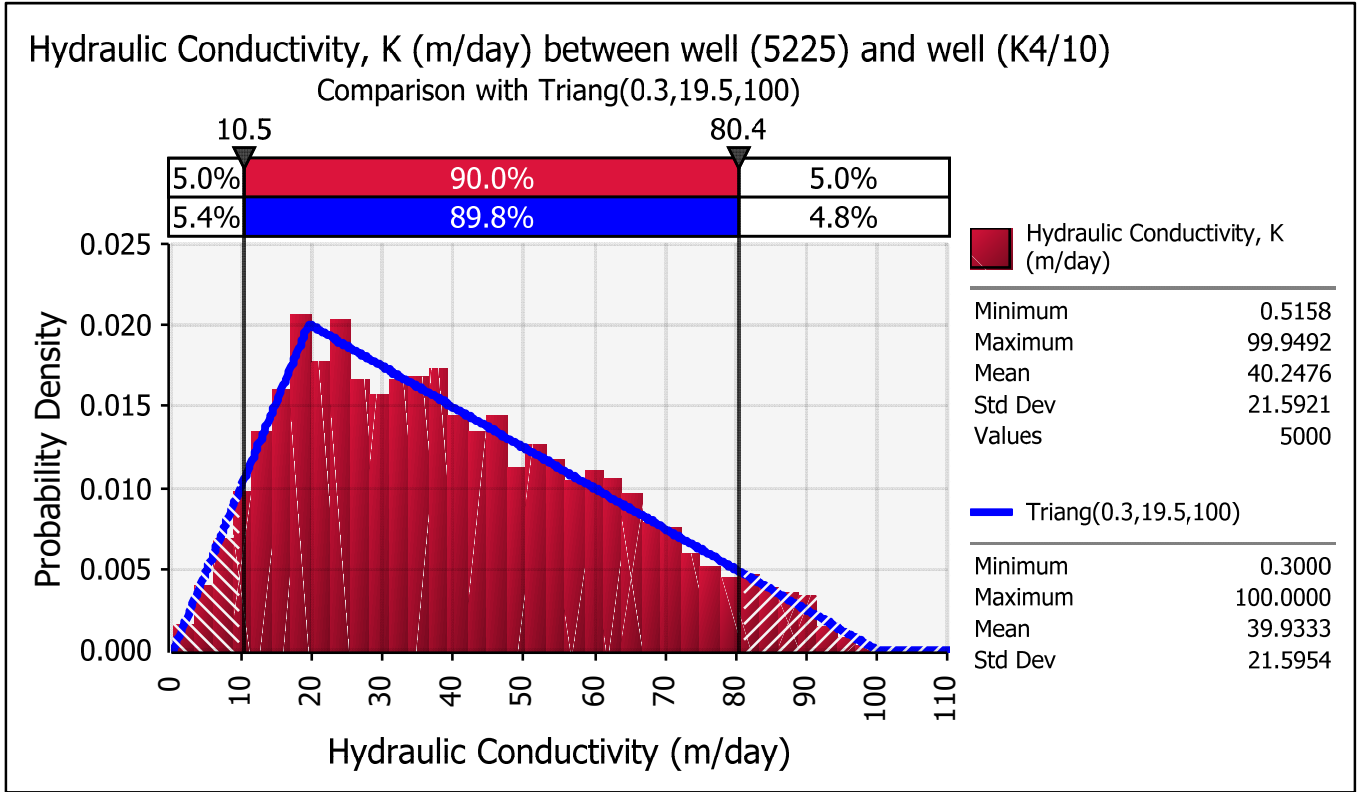

Figure A4. Hydraulic Conductivity between Well (5225) and Well (K4/10) with an Iteration Number of 5000 


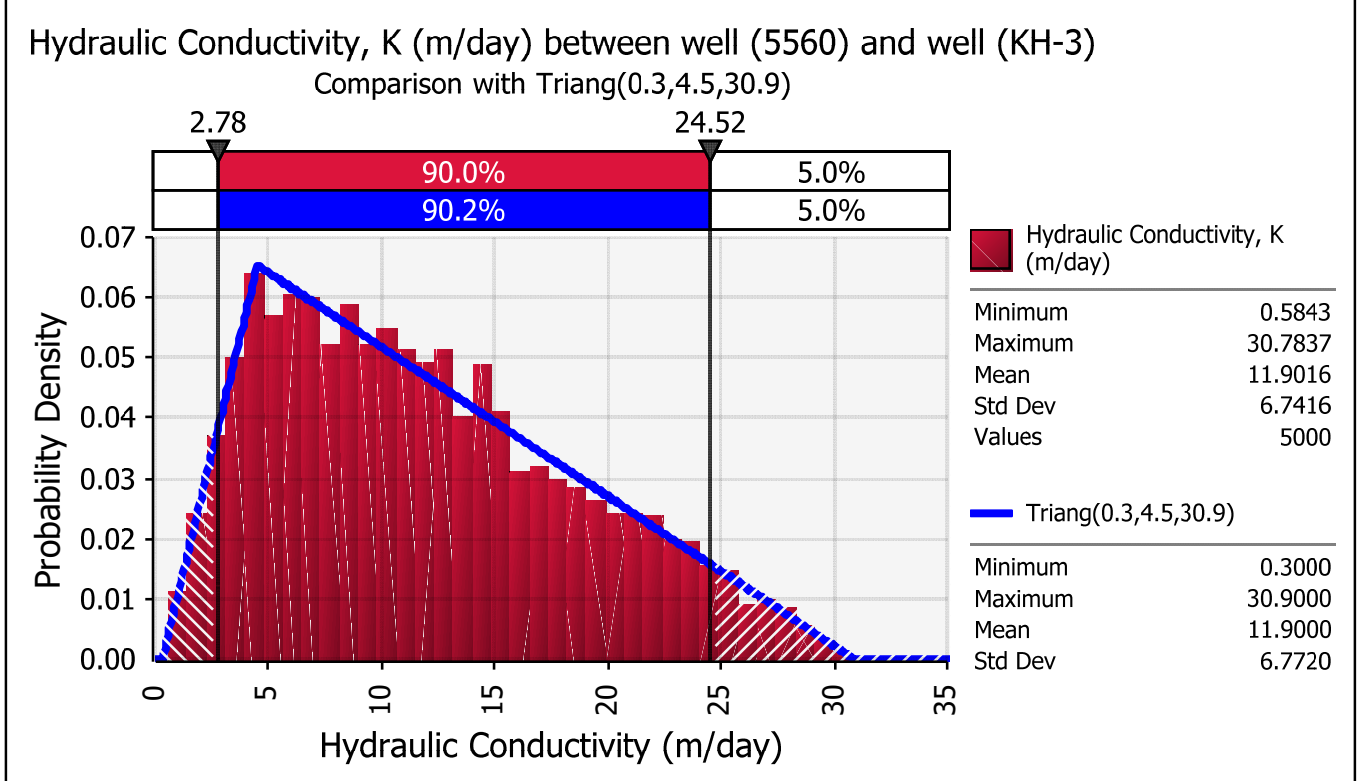

Figure A5. Hydraulic Conductivity between Well (5560) and Well (KH-3) with an Iteration Number of 5000

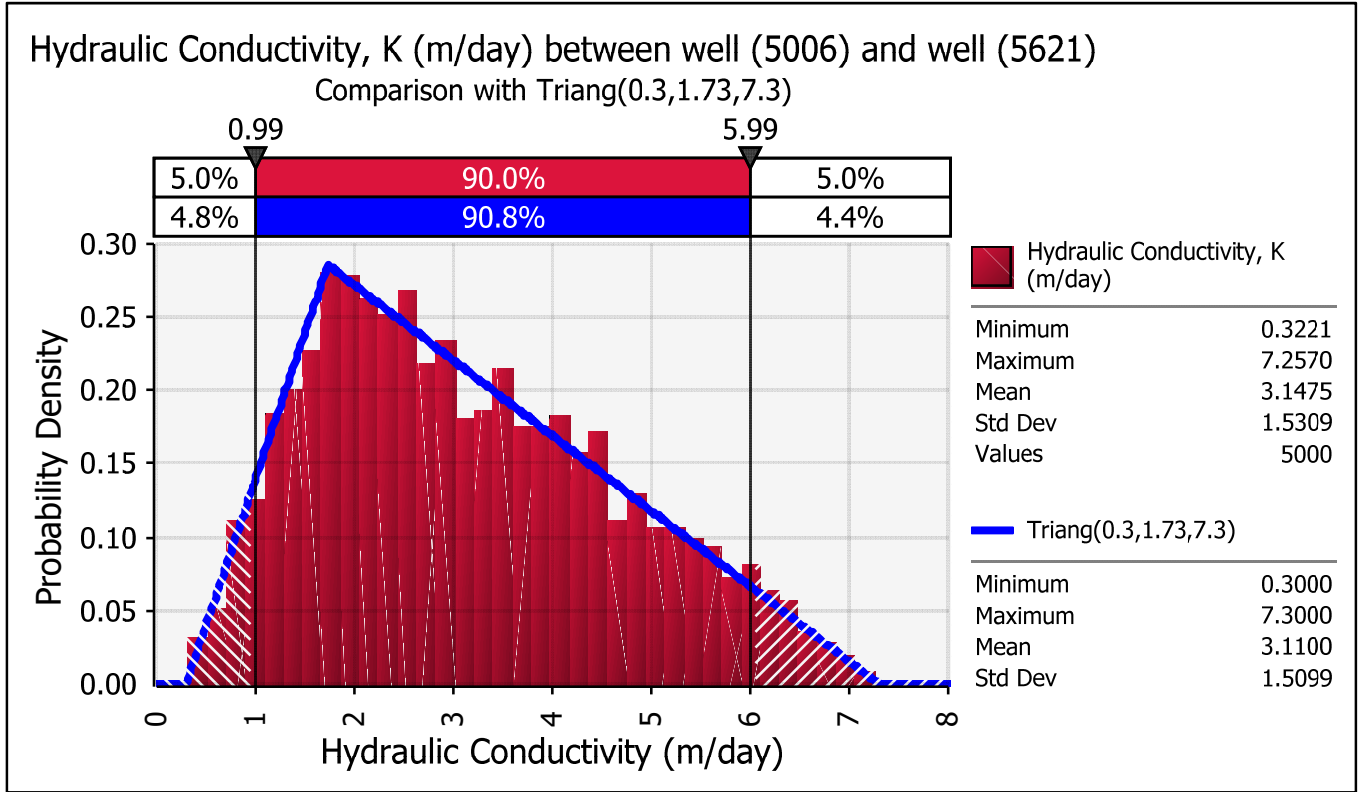

Figure A6. Hydraulic Conductivity between Well (5006) and Well (5621) with an Iteration Number of 5000 


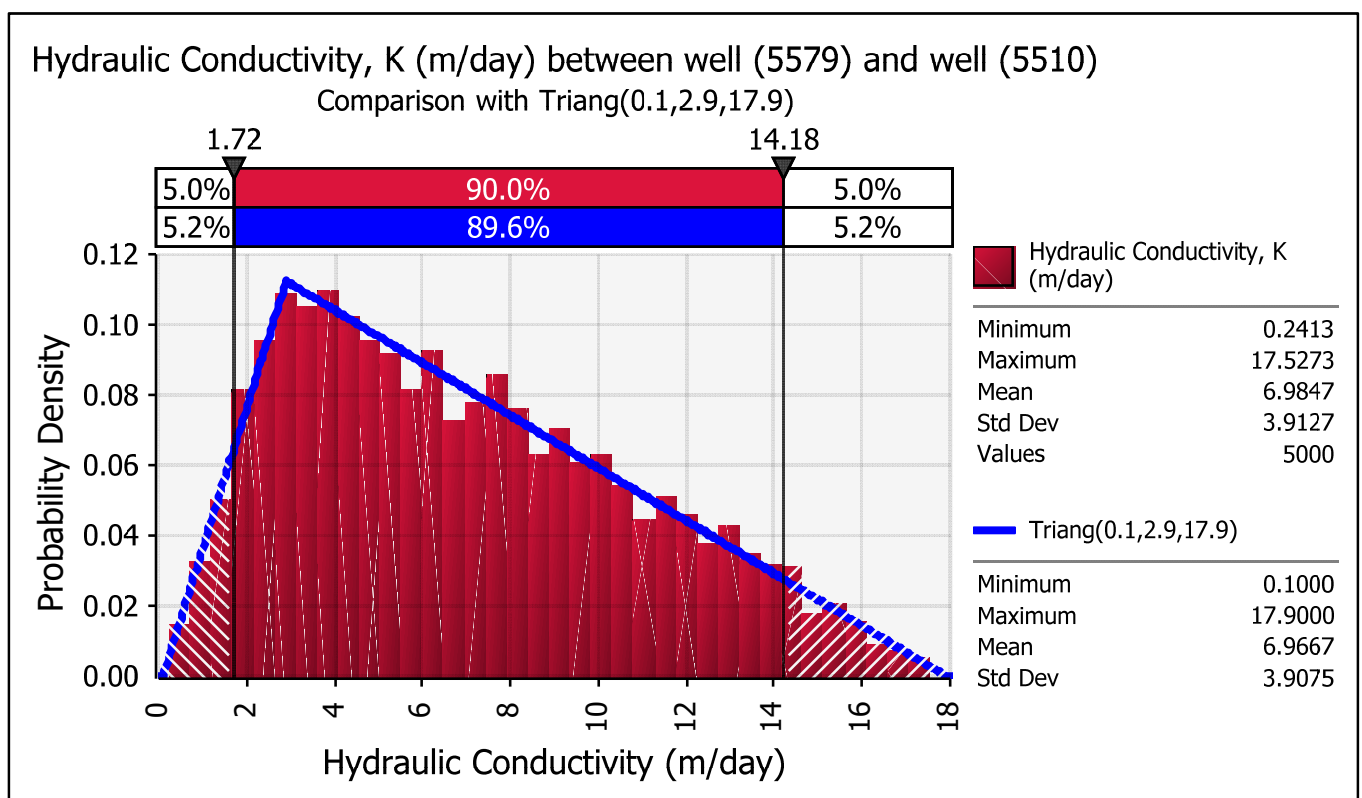

Figure A7. Hydraulic Conductivity between Well (5579) and Well (5510) with an Iteration Number of 5000

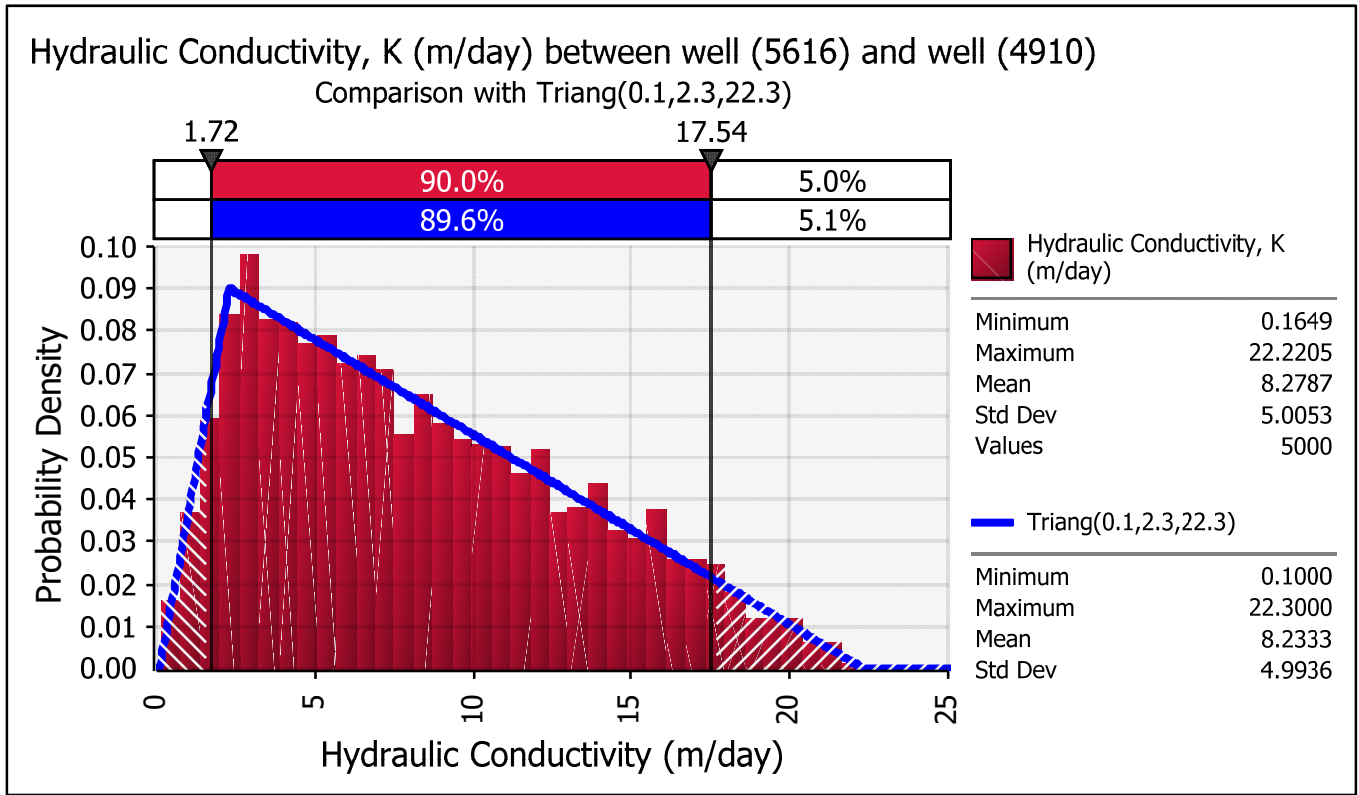

Figure A8. Hydraulic Conductivity between Well (5616) and Well (4910) with an Iteration Number of 5000 


\section{Appendix B}

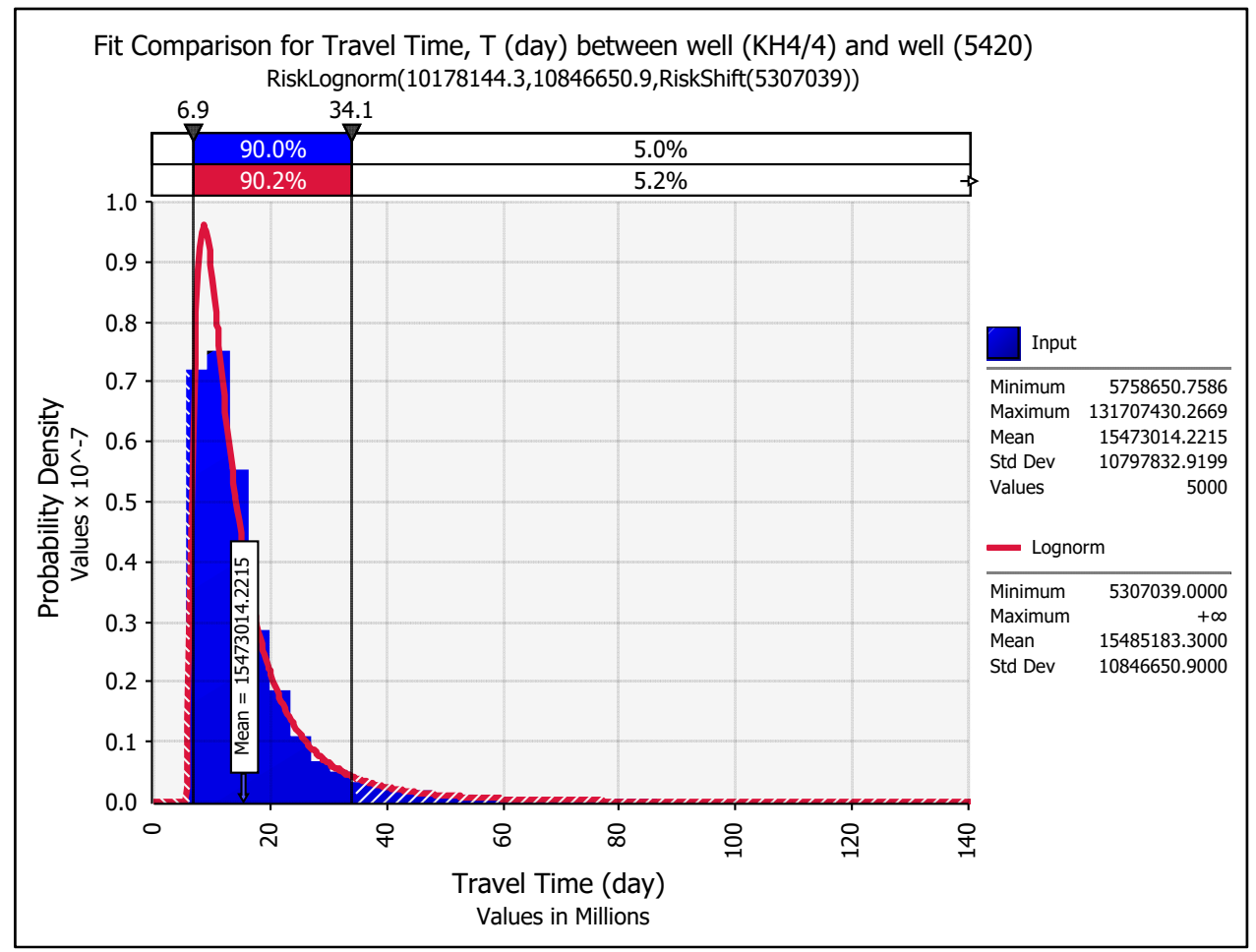

Figure B1. Fit Comparison for Travel Time between Well (KH4/4) and Well (5420)

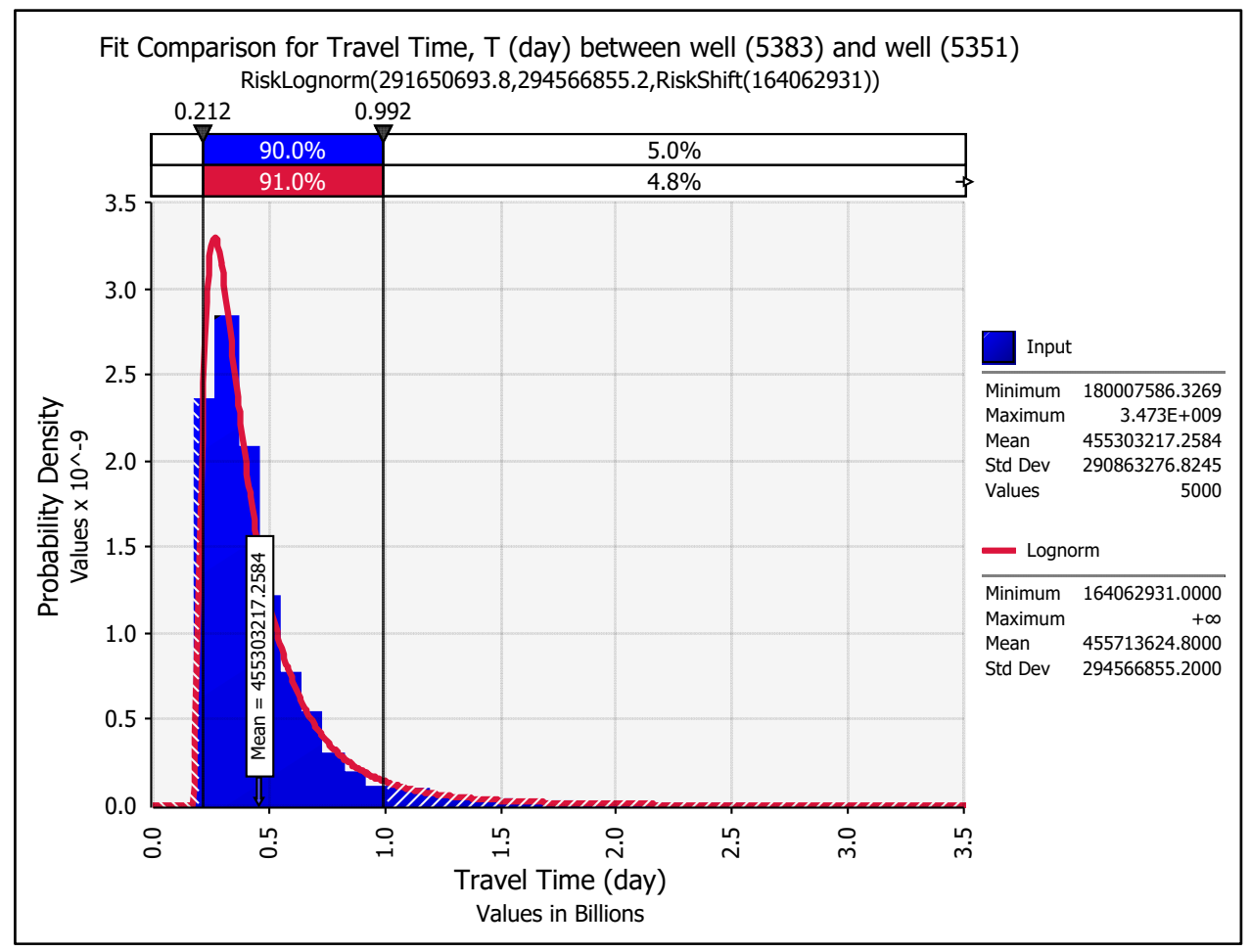

Figure B2. Fit Comparison for Travel Time between Well (5383) and Well (5351) 


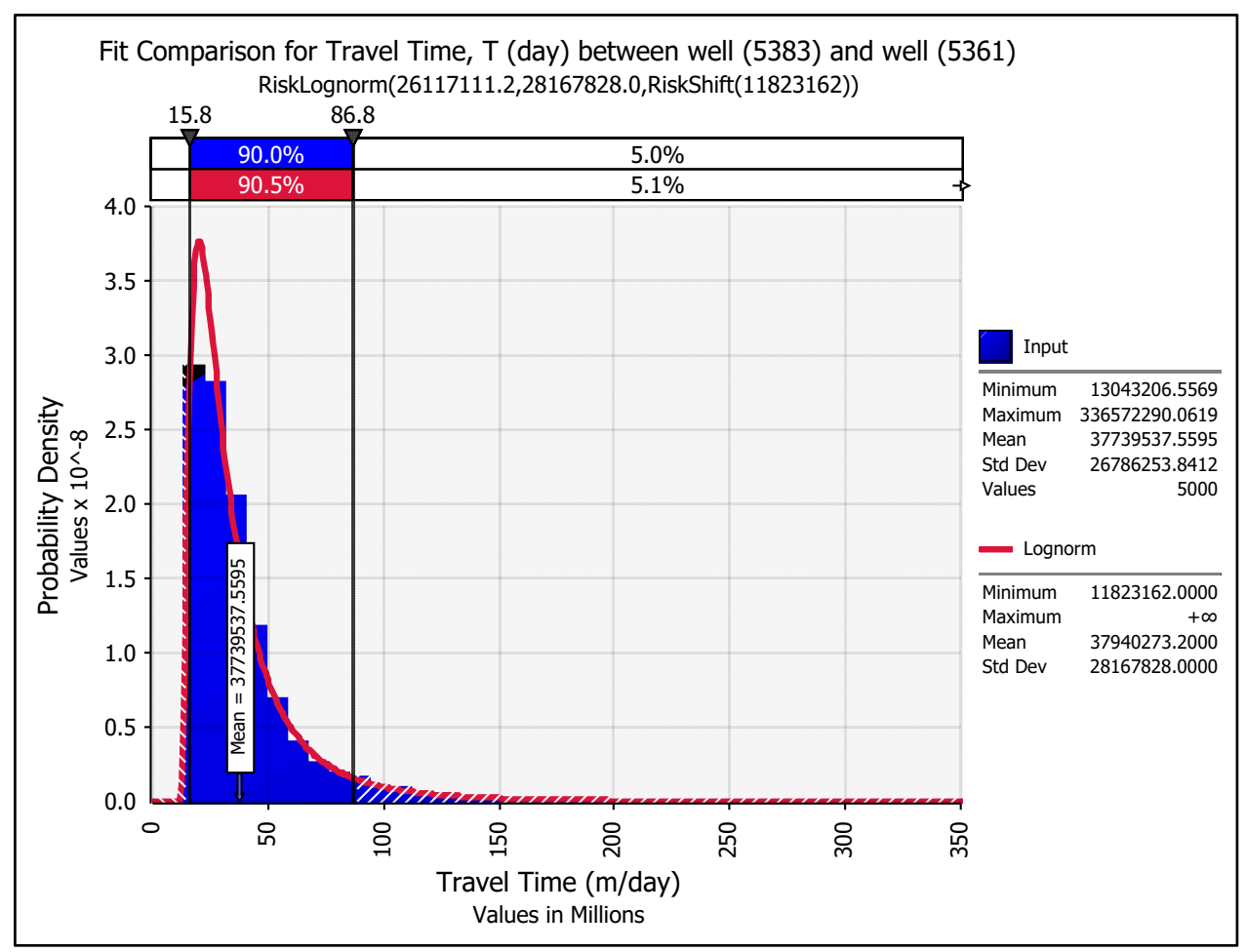

Figure B3. Fit Comparison for Travel Time between Well (5383) and Well (5361)

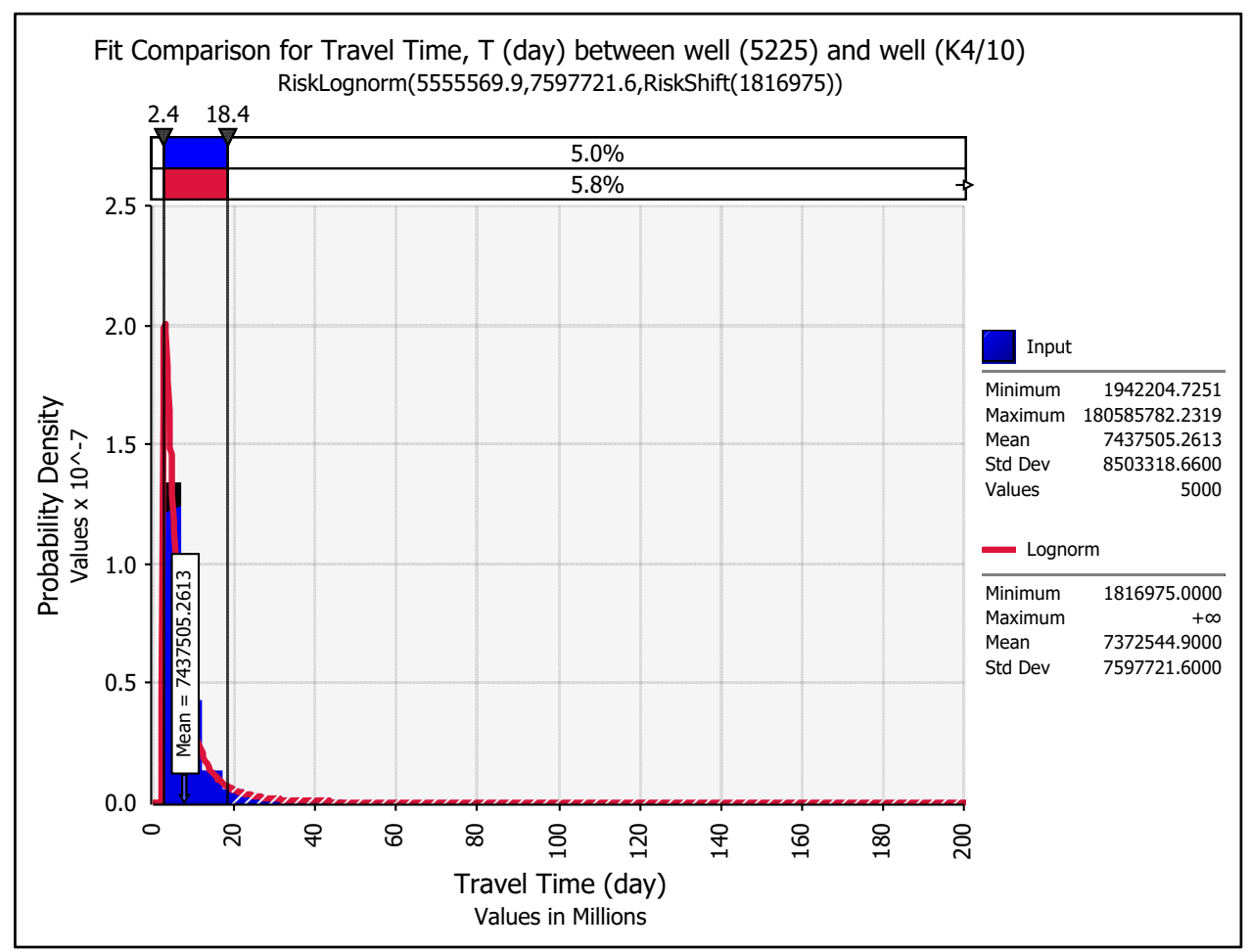

Figure B4. Fit Comparison for Travel Time between Well (5225) and Well (K4/10) 


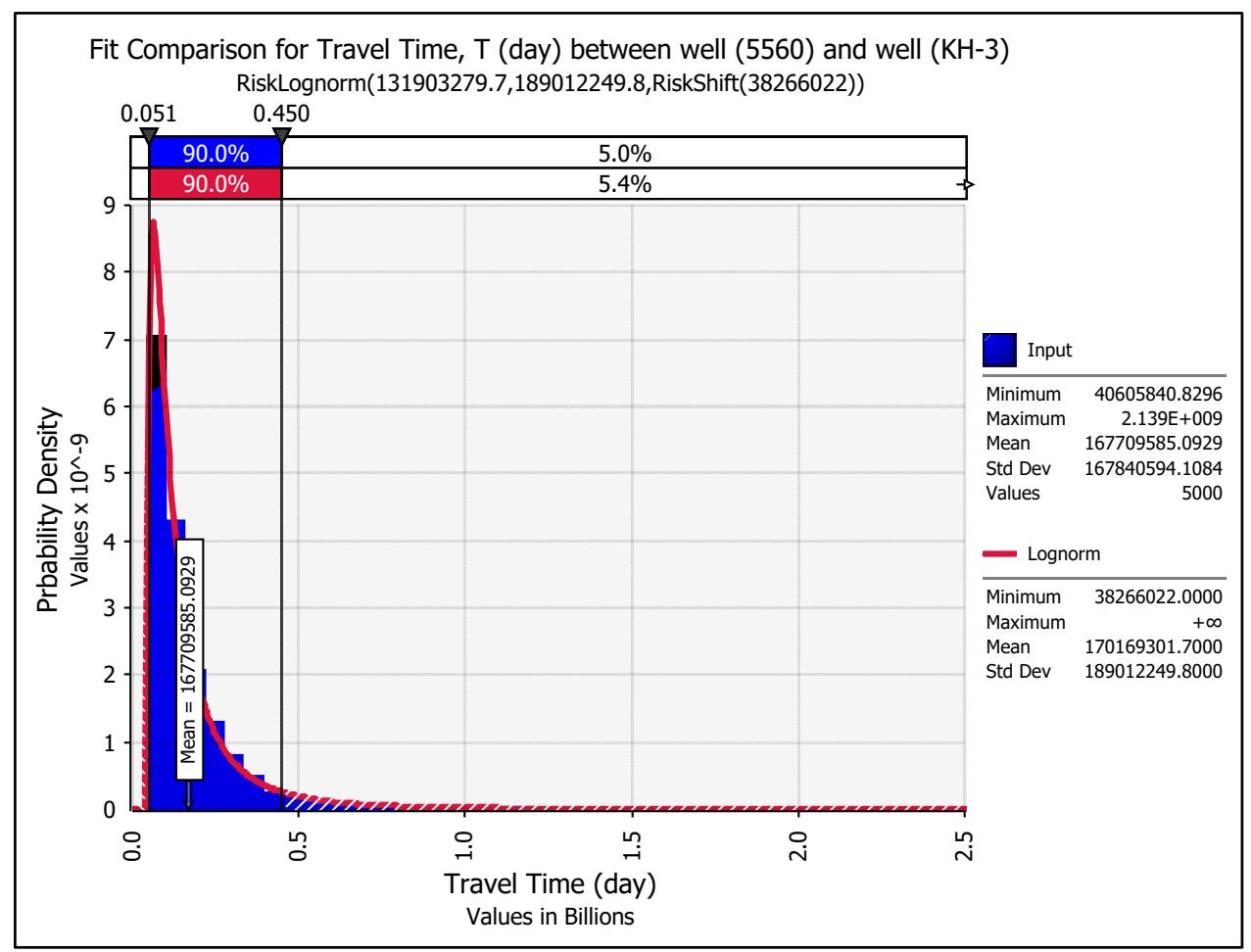

Figure B5. Fit Comparison for Travel Time between Well (5560) and Well (KH-3)

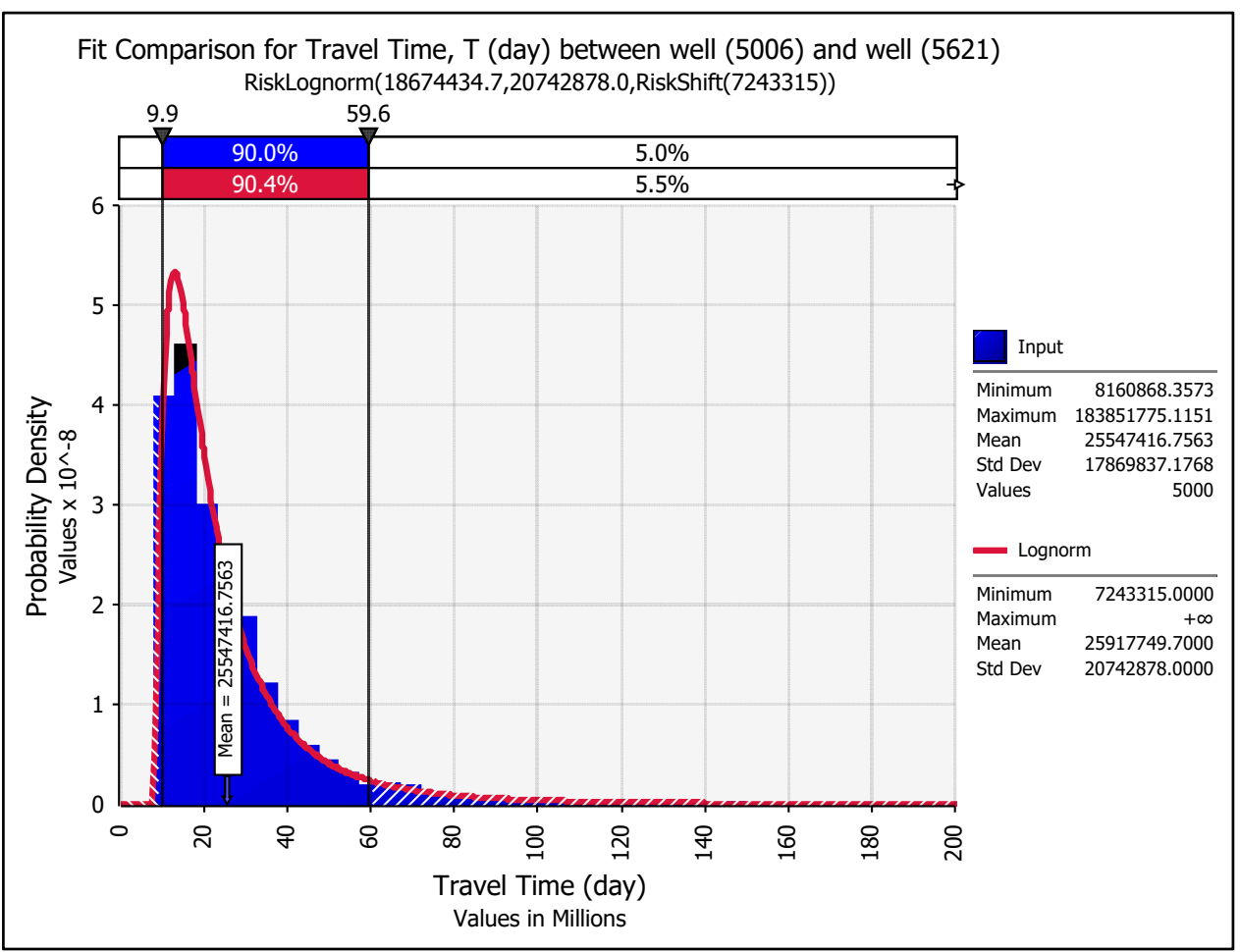

Figure B6. Fit Comparison for Travel Time between Well (5006) and Well (5621) 


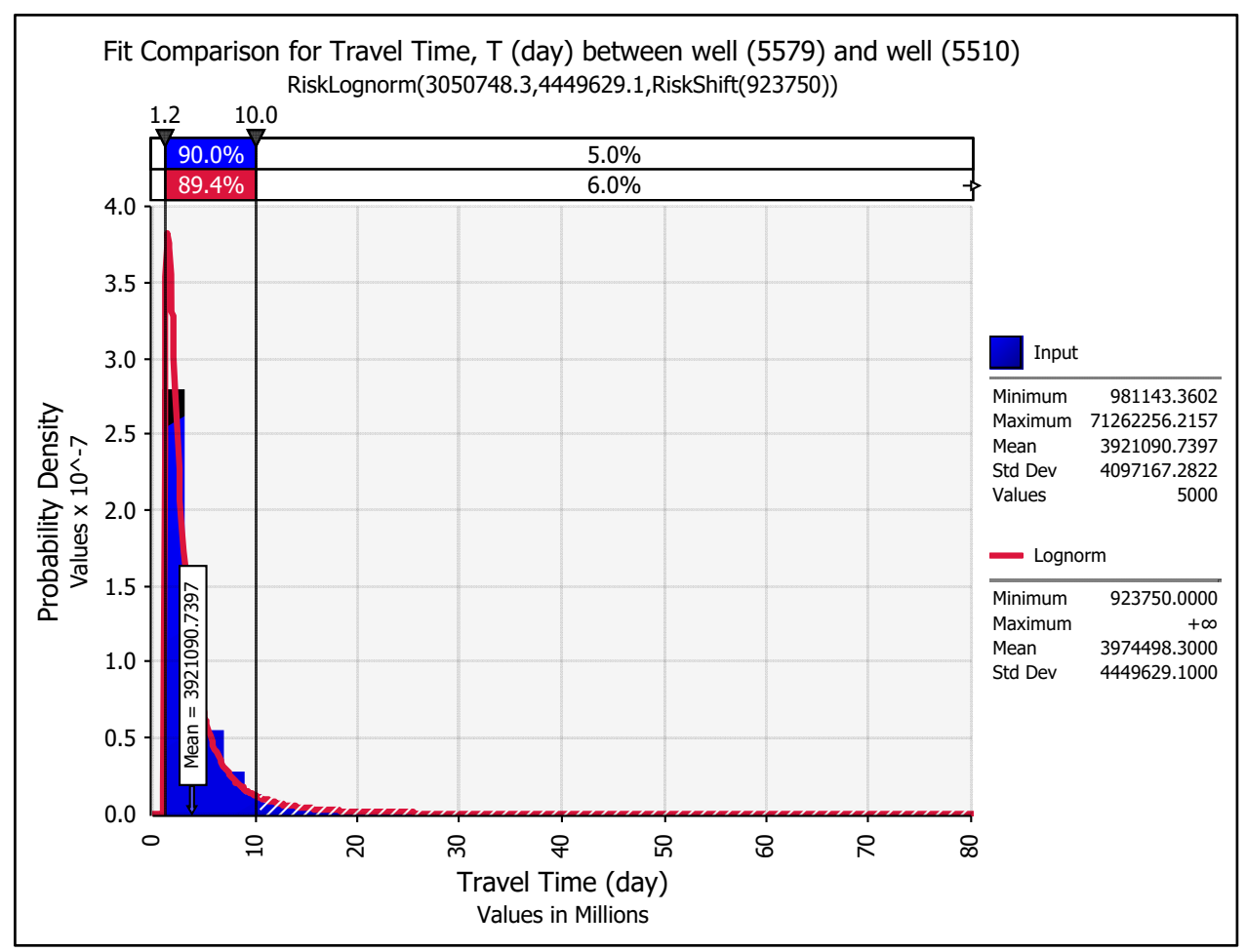

Figure B7. Fit Comparison for Travel Time between Well (5579) and Well (5510)

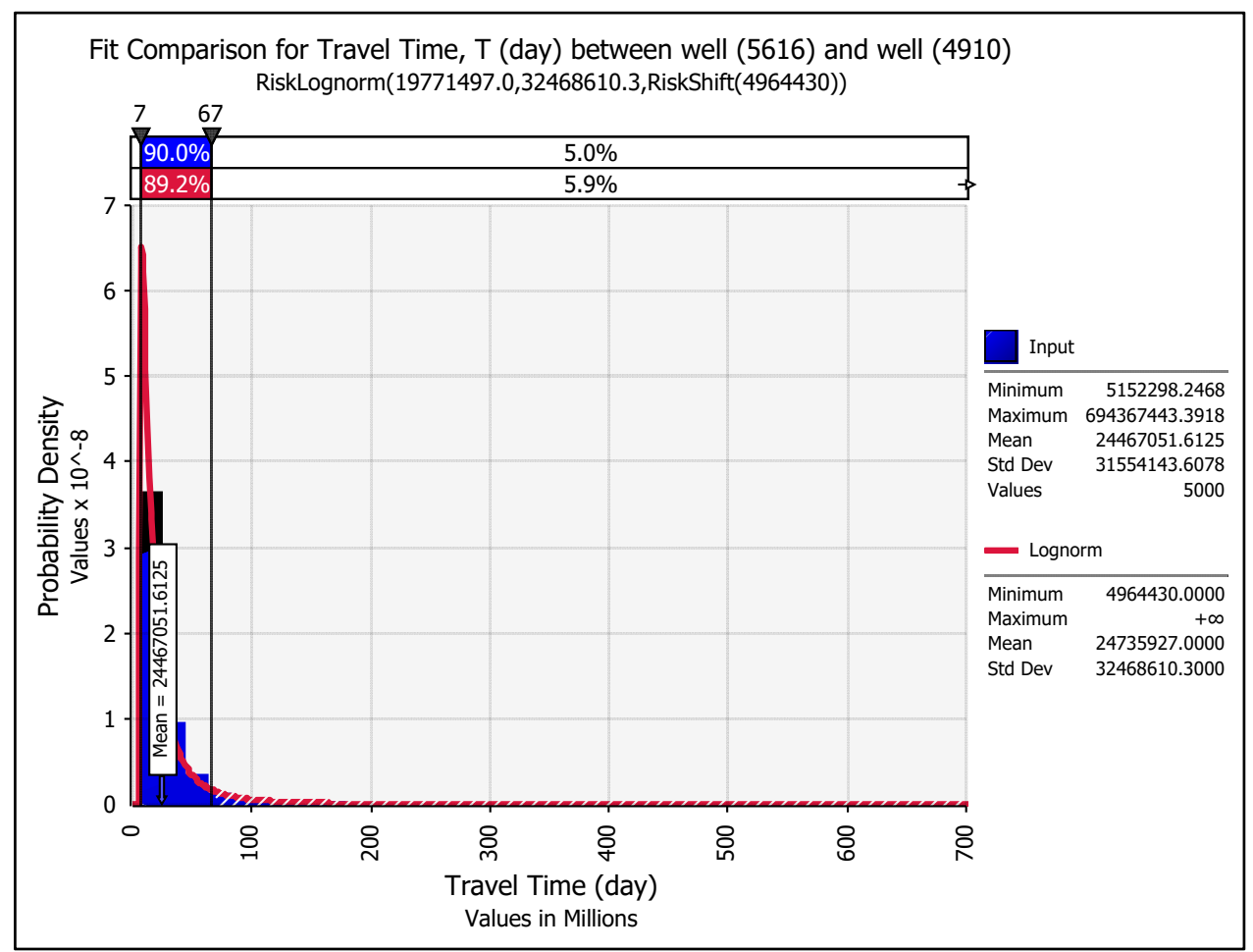

Figure B8. Fit Comparison for Travel Time between Well (5616) and Well (4910)

\section{Copyrights}

Copyright for this article is retained by the author(s), with first publication rights granted to the journal.

This is an open-access article distributed under the terms and conditions of the Creative Commons Attribution license (http://creativecommons.org/licenses/by/4.0/). 